\title{
Towards the dehydration of ethanol using pervaporation cross-linked poly(vinyl
} alcohol)/graphene oxide membranes

Roberto Castro-Muñoz ${ }^{a}$ b, c, Juan Buera-González ${ }^{a}$, Óscar de la Iglesia ${ }^{a}$ d, Francesco Galiano $^{\mathrm{b}}$, Vlastimil Fíla $^{\mathrm{c}}$, Magdalena Malankowska $^{\mathrm{a}}$, César Rubio ${ }^{\mathrm{a}}$, Alberto Figoli ${ }^{\mathrm{b}}$, Carlos Téllez ${ }^{\mathrm{a}}$, Joaquín Coronas ${ }^{\mathrm{a},{ }^{*}}$

(a) Chemical and Environmental Engineering Department, Instituto de Nanociencia de Aragón (INA) and Instituto de Ciencia de Materiales de Aragón (ICMA), Universidad de Zaragoza-CSIC, 50018 Zaragoza, Spain. Email: coronas@unizar.es

(b) Institute on Membrane Technology, ITM-CNR, c/o University of Calabria, P. Bucci 17c, 87030 Rende (CS), Italy

(c) University of Chemistry and Technology Prague, Technická 5, 16628 Prague 6, Czech Republic

(d) Centro Universitario de la Defensa Zaragoza, Academia General Militar, 50090 Zaragoza, Spain

\section{Abstract}

Highly hydrophilic inorganic material graphene oxide (GO) was successfully prepared and incorporated into a cross-linked poly(vinyl alcohol) (PVA) matrix. The obtained mixed matrix membranes (MMMs) have been used for the dehydration of ethanol (10:90\% water-ethanol) by pervaporation (PV), monitoring their performance in terms of total permeate flux, partial components fluxes, as well as their separation factor. The effect of filler was analyzed by doubling the GO content (at $0.5,1.0$, and 2.0 wt.\%) in the MMMs. 
25 A complete analysis of the operating temperature (between $40-70^{\circ} \mathrm{C}$ ) was carried out by means of Arrhenius relationship. Moreover, the membranes were characterized by field 27 emission scanning electron microscopy (FESEM), transmission electron microscopy (TEM), differential scanning calorimetry (DSC), thermo-gravimetric analysis (TGA), X-ray 29 diffraction (XRD), Fourier transformed infrared spectroscopy (FTIR), measurements of degree of swelling (uptake), water contact angle (CA) and mechanical properties. At 40 ${ }^{\circ} \mathrm{C}$, the best performance was provided by the MMMs containing $1 \mathrm{wt} . \% \mathrm{GO}$, showing a separation factor of 263 and a permeate flux of about $0.137 \mathrm{~kg} \cdot \mathrm{m}^{-2} \cdot \mathrm{h}^{-1}$ (in which 0.133 $\mathrm{kg} \cdot \mathrm{m}^{-2} \cdot \mathrm{h}^{-1}$ corresponds to water). This represents a $75 \%$ enhancement of the original permeation rate of pristine cross-linked PVA membranes. Taking into account the promising results, it is likely that these MMMs will provide featured benefits in green processes, e.g. ethanol purification by means of less-energy consumption.

Keywords: pervaporation; poly (vinyl alcohol); cross-linking; mixed matrix membrane; ethanol dehydration; graphene oxide.

\section{Nomenclature}

42 PV: Pervaporation

43 PVA: Poly(vinyl alcohol)

44 CA: water contact angle

$45 \mathrm{~J}$ : Permeate flux, $\mathrm{kg} \cdot \mathrm{m}^{-2} \cdot \mathrm{h}^{-1}$

46 a: Separation factor

47 FESEM: Field emission scanning electron microscopy

48 DSC: Differential scanning calorimetry

49 MMM: Mixed matrix membrane

50 TGA: Thermo-gravimetric analysis 
51 GO: Graphene oxide

52 XRD: X-ray diffraction

\section{Introduction}

Membrane-based technologies have attracted considerable attention for different types

56 of applications (e.g. in food, petrochemical and environmental fields). In particular,

57 pervaporation (PV), as a merge of evaporation and permeation processes, has been

58 consistently proposed for the separation of different types of azeotropic and close-boiling compounds mixtures. The benefit of using this membrane process for such purposes is due to its high selectivity, efficiency and low-energy requirements [1,2]; the latest being

61 the main feature of PV that indeed makes it attractive to be considered as a "Green"

62 process. These mechanisms are currently encouraged to meet the "Twelve Principles of

63 Green Chemistry". Such principles, well-established by Anastas and Warner [3], are

64 aimed to preserve the environment through implementation of green chemistry methods.

65 Moreover, PV is a good candidate for the replacement of the conventional distillation, which, for instance, carries out the separation of azeotropic mixtures at large-scale in

67 petrochemical industry. PV has demonstrated the ability to separate different types of 68 azeotropic mixtures, including organic-water, organic-organic and water-organic [4,5]. At 69 industrial level, PV has found its growing use in industry towards water-organic mixtures, 70 which implies the dehydration of organics to reach higher purification degrees, e.g. in 71 ethanol [6], isopropanol [7] and acetonitrile [8]. To date, the dehydration of ethanol is the 72 most sought application due to its direct impact on commercial value. According to the 73 IEA (Industrial Ethanol Association, http://www.industrial-ethanol.org), the main market 74 for ethanol concerns the manufacture of beverages, fuels and a multiple of industrial 
75 applications related to pharmaceuticals, cosmetics, detergents, printing inks, paints, coatings, medical uses, production of polymers and chemicals, to mention just a few. This

77 makes the ethanol production continuously grow, e.g. over 100 billion liters demand was reported by 2017 [9], and its demands is expected to increase in coming years. Typically, ethanol can be produced by fermentation or from direct hydration of ethylene. Moreover, regardless of its production process, the final product is usually a diluted aqueous solution

81 and at a large-scale level, the ethanol is processed by distillation in order to concentrate

it. The separation of ethanol and water is complicated due to the fact that ethanol and water form an azeotrope at $95.6 \mathrm{wt} . \%$ of ethanol [10]. Thereby, it is a difficult task to produce pure ethanol from an azeotropic mixture by conventional distillation: at the azeotrope vapor and liquid compositions are the same. Herein, the PV has been introduced as a promising alternative towards such purpose. When dealing with the dehydration of any organic (e.g. ethanol), it is inevitable to address the use of hydrophilic membranes. At this point, several types of hydrophilic polymers have been proposed and investigated as membrane materials, such as polyimides [6], sodium alginate [11], polybenzimidazole (PBI) [12], chitosan [13], polyacrylonitrile (PAN) [14] and poly(vinyl

91 alcohol) (PVA) [7]. Among all these polymers, PVA has been the only one to be 92 consolidated at industrial level. For instance, DeltaMem AG (http://www.deltamem.ch) is 93 a company that currently manufactures and commercializes cross-linked PVA 94 membranes for PV applications. Nowadays, one of the most successful trends in 95 enhancing the performance of polymeric membranes implies the embedding of inorganic 96 materials, generating the so-called mixed matrix membranes (MMMs). These combine 97 the strengths of inorganic and polymeric membranes to ideally reach an enhanced 
synergistic performance. To date, some MMMs based on PVA have been proposed for

ethanol dehydration displaying acceptable separation performance, e.g. those containing $\operatorname{MWCNT}\left(\mathrm{J}=0.080 \mathrm{~kg} \cdot \mathrm{m}^{-2} \cdot \mathrm{h}^{-1}, \alpha=500\right)[15]$ and $\mathrm{ZIF}-8-\mathrm{NH}_{2}\left(\mathrm{~J}=0.120 \mathrm{~kg} \cdot \mathrm{m}^{-2} \cdot \mathrm{h}^{-1}, \alpha=200\right)$ [16]. In this work, the possibility of incorporating a highly hydrophilic material, like graphene oxide (GO), into cross-linked PVA membranes, to achieve better performance, was studied. GO is a layered material produced by the oxidation of graphite. GO sheets are highly oxygenated having hydroxyl and epoxy functional groups on their basal planes, in addition to carbonyl and carboxyl groups located at the sheet edges. These functional groups provide a high hydrophilic profile to the material [17], which has been noted in PVA during organic-organic separations $[18,19]$. Thereby, the aim of this work was to analyze the effect of GO on the performance of cross-linked PVA MMMs used in ethanol dehydration. To the best of our knowledge, there is no report about this [5]. The effect of operating temperature on total permeate flux and separation factor was investigated by doubling the GO content (at $0.5,1.0$, and 2.0 wt.\%) in the MMMs. Moreover, the pristine membrane and MMMs were characterized by thermogravimetric analysis (TGA), differential scanning calorimetry (DSC), field emission scanning electron microscopy (FESEM), transmission electron microscopy (TEM), degree of swelling (uptake), X-ray diffraction (XRD), Fourier transformed infrared spectroscopy (FTIR), measurements of water contact angle and mechanical properties.

\section{Experimental}

2.1. Materials 
Poly (vinyl alcohol) (PVA, MW:130,000), glutaraldehyde (grade II, 25 wt.\%) and

121 hydrochloric acid $(\mathrm{HCl})$ were acquired from Sigma-Aldrich and used without further

122 purification.

\subsection{Synthesis of graphene oxide}

125 Graphene oxide (GO) was synthesized following the procedure described by Castarlenas 126 et al. [20], according to the Hummers' method [21]. Basically, the graphite is oxidized by 127 treatment with $\mathrm{KMnO}_{4}$ and $\mathrm{NaNO}_{3}$ in concentrated $\mathrm{H}_{2} \mathrm{SO}_{4}$. In a round bottom flask, 128 sodium nitrate $(1.5 \mathrm{~g})$ was dissolved in $70 \mathrm{~mL}$ of concentrated sulfuric acid. The dispersion was put under stirring at room temperature until the $\mathrm{NaNO}_{3}$ was totally dissolved 130 (approximately 5-10 $\mathrm{min}$ ). Therefore, graphite (3.0 g) (with a particle size of ca. $5 \mu \mathrm{m}$, 131 supplied by Richard Anton KG) was added to the solution under gentle stirring for about $13230 \mathrm{~min}$ to facilitate a homogeneous suspension. Later, $\mathrm{KMnO}_{4}(9.0 \mathrm{~g})$ was gradually 133 added to the suspension to avoid the increase of the flask temperature due to the heat 134 generated during redox reaction. Once the addition of $\mathrm{KMnO}_{4}$ was completed, the 135 temperature of the solution was slowly raised up to $35^{\circ} \mathrm{C}$ and maintained for 30 min under 136 stirring. To facilitate the control of the exothermic reaction an ice bath was put under the 137 glass balloon. A brownish gray paste was formed. Then, by means of a Pasteur pipette, $138140 \mathrm{~mL}$ of deionized water was slowly added to the slurry considering that the smoke 139 production was very fast. Once the deionized water was added, the suspension was kept 140 stirring overnight at $95^{\circ} \mathrm{C}$ and later, $500 \mathrm{~mL}$ of deionized water was added followed by $14120 \mathrm{~mL} \mathrm{H} \mathrm{H}_{2}$ that reduced the residual permanganate. The round bottom flask was kept 142 under stirring at $95^{\circ} \mathrm{C}$ for $3 \mathrm{~h}$. The resulting mixture was filtered and washed using a 10 
wt.\% aqueous $\mathrm{HCl}$ solution. Finally, $\mathrm{GO}$ was centrifuged and washed with water 4 times at $10000 \mathrm{rpm}$ for $15 \mathrm{~min}$ (Beckman Coulter, Allegra $\mathrm{x}-15 \mathrm{R}$ ), reaching the neutral $\mathrm{pH}$, and dried at $80^{\circ} \mathrm{C}$ overnight obtaining $4.2 \mathrm{~g}$ of a light brown solid.

\subsection{Mixed matrix membrane preparation}

PVA/GO MMMs were prepared by dense-film casting method and solvent evaporation. PVA powder $(3 \mathrm{~g})$ was dissolved under stirring in $100 \mathrm{~mL}$ of distilled water at $90{ }^{\circ} \mathrm{C}$. The obtained solution was filtered to remove any insoluble impurities. GO was added to the PVA solution to produce the dope suspension that was stirred during $12 \mathrm{~h}$ and processed by sonication twice (30 min each). Afterwards, the in situ cross-linking procedure was performed by adding $0.1 \mathrm{~mL}$ of $\mathrm{GA}$ and $0.1 \mathrm{~mL}$ of $\mathrm{HCl}$ to the dope. This was stirred during 15 min, cast on a clean glass plate and then dried in an oven at $40^{\circ} \mathrm{C}$ during 2 days. Finally, the MMMs were peeled off of the glass plate. The GO loading for the MMMs was varied at $0.5,1$, and $2 \mathrm{wt} . \%$. Figure 1 shows typical examples of the prepared membranes for this study, with a membrane thickness of $40 \pm 2 \mu \mathrm{m}$ (measured with digital micrometer Mitutoyo with an accuracy of $1 \mu \mathrm{m})$. It can be observed that the presence of GO particles provides a darker colour on the MMM surface.

Figure 1. Pure cross-linked PVA membrane and its MMMs-GO with $1 \mathrm{wt} . \%$ of filler.

\subsubsection{Membrane characterization}

Field emission scanning electron microscopy (FESEM). The morphological structure of the membrane surface and cross-section of the cross-linked-PVA and its MMMs were 
evaluated using a field emission scanning electron microscope (FEI Inspect, F50 operated at $20 \mathrm{kV}$ ). The cross-sections were obtained by cryogenic fracture immersion of the samples in liquid $\mathrm{N}_{2}$. The samples were attached to SEM carbon stubs with a diameter of $2.54 \mathrm{~cm}$ using two-sided adhesive tape. The samples were coated through a sputtering process with gold-palladium ( $\mathrm{Au} / \mathrm{Pd}$ ). The corresponding images were captured at 171 suitable magnification.

172 Transmission electron microscopy (TEM). The distribution and dimensions of GO sheets 173 in cross-linked PVA-GO 1 wt.\% membrane were obtained from TEM images (FEI TECNAI 174 T20 transmission microscope at $200 \mathrm{kV}$ ). The membrane sample was embedded in a 175 polymeric resin and cut with an ultramicrotome to the required size.

176 Differential scanning calorimetry (DSC). Differential scanning calorimetry (DSC) was 177 conducted on a ca. $10 \mathrm{mg}$ sample using a Mettler Toledo DSC822e system. The $T_{g}$ 178 routine was performed in two cycles from room temperature up to $450{ }^{\circ} \mathrm{C}$ at the 179 temperature ramping of $20^{\circ} \mathrm{C} \cdot \mathrm{min}^{-1}$. The $T_{g}$ determination was done in triplicate.

180 Thermo-gravimetric analysis (TGA). Thermogravimetric analysis (TGA) was performed 181 using a Mettler Toledo TGA/SDTA $851^{\mathrm{e}}$. The analysis was carried out by placing the 182 sample (approximately $10 \mathrm{mg}$ ) in an alumina crucible and heating the samples up to 750 $183{ }^{\circ} \mathrm{C}$ at a ramp of $10^{\circ} \mathrm{C} \cdot \mathrm{min}^{-1}$ under air flow of $40 \mathrm{~mL}(\mathrm{STP}) \cdot \mathrm{min}^{-1}$.

$184 X$-ray diffraction $(X R D)$. X-ray diffraction $(X R D)$ patterns of the $\mathrm{GO}$ and membranes were 185 obtained by using a Pananalytical Empyrean multipurpose diffractometer ( $40 \mathrm{kV}, 20 \mathrm{~mA}$ ) 186 with a Cu-Ka $(\lambda=0.1542 \mathrm{~nm})$ anode, from $2 \theta$ of $2.5^{\circ}$ to $40^{\circ}$ with a $0.03^{\circ}$ step $\cdot \mathrm{s}^{-1}$.

187 Fourier transformed infrared spectroscopy (FTIR). FTIR was performed on GO, 188 glutaraldehyde, pristine PVA, cross-linked PVA and the cross-linked PVA-GO 1 wt.\% 
samples, using a Bruker Vertex 70 FTIR spectrometer equipped with a DTGS detector and a Golden Gate diamond ATR accessory. The spectra were recorded in the 4000$600 \mathrm{~cm}^{-1}$ wavenumber range at a resolution of $4 \mathrm{~cm}^{-1}$.

Uptake. The uptake, known as swelling degree, of the cross-linked PVA and MMM membranes was investigated for the 10:90 wt.\% water-ethanol mixture following the procedure previously reported by Choi et al. [15]. Three small pieces of membranes (1x5 $\mathrm{cm}$ ) were weighed and immersed in the mixture at $40^{\circ} \mathrm{C}$ for $48 \mathrm{~h}$. The wet membranes were quickly wiped with tissue paper to remove the excess of free liquid on their surface and weighed with a digital balance (Kern, ABJ220-4NM, Germany) with an accuracy of $0.001 \mathrm{~g}$. The uptake was calculated as follows:

$$
\text { Uptake }(\%)=\frac{W_{w} W_{d}}{W_{d}} \times 100
$$

where $W_{w}$ and $W_{d}$ were the weights of the wet and dry membranes, respectively.

Water contact angle (CA). The water contact angle measurements were performed using ultrapure water by the method of the sessile drop using the Krüss DSA 10 MK2 instrument. The average and standard deviation values were determined for three measurements.

Mechanical properties. Mechanical properties of pristine cross-linked PVA membranes and PVA MMMs were determined using a Zwick/Roell Z2.5 test unit (BTC-FR2.5TN-D09, Germany). Measurements were carried out at room temperature $\left(25{ }^{\circ} \mathrm{C}\right)$ using a membrane sample of $1 \times 5 \mathrm{~cm}$. The samples were extended at the constant elongation rate of $5 \mathrm{~mm} \cdot \mathrm{min}^{-1}$ until their break. Elongation at break, Young's modulus and tensile strength were therefore determined. For each membrane, at least four samples were 
211 analyzed and the average and standard deviation were calculated. Mechanical tests were

212 carried out on all the investigated membranes before and after soaking them in a water-

213 ethanol solution (10:90 wt. \%) at $25^{\circ} \mathrm{C}$ for $24 \mathrm{~h}$.

214

215

\subsubsection{Pervaporation performance}

216 The PV tests were performed in a semi-continuous laboratory-scale setup. A 10:90 wt.\%

217 water-ethanol feed solution $(1000 \mathrm{~mL})$ was poured in the feed tank. The operating 218 temperature (at $40,50,60$ and $70^{\circ} \mathrm{C}$ ) was controlled with an accuracy of $0.01^{\circ} \mathrm{C}$ using a

219 thermometer, which was placed inside the membrane cell (in contact with the azeotropic 220 mixture). The vacuum on permeate side was set at 3-4 mbar using a RV3 two-stage 221 vacuum pump (Edwards, UK).

222 The membranes, with an area of $11.7 \mathrm{~cm}^{2}$, were located on a porous support within the 223 membrane cell. The permeated vapor was condensed and collected in a glass trap placed 224 in a liquid nitrogen condenser. Up to reach the steady-state, the permeates were collected 225 for $8 \mathrm{~h}$ and weighted to calculate the total permeate flux $(\mathrm{J})$ as follows:

$$
J=\frac{Q}{A x t}
$$

227 where $Q$ is the weight of the permeate $(\mathrm{kg}), A$ is the membrane area $\left(\mathrm{m}^{2}\right)$ and $t$ is the 228 operating time (h). The partial flux $\left(J_{i}\right)$ for component $i$ was determined by multiplying its 229 weight fraction $\left(y_{i}\right)$ in the collected permeate by the total permeate flux $(J)$, as Eq. (3) 230 describes:

$$
J_{i}=y_{i} \times J
$$

232 The separation factor ( $\alpha$ ) was calculated according to Eq. 4: 
234 where $y$ and $x$ are the weight fractions of the components in the permeate and feed, 235 respectively. The permeate samples were weighed to determine the membrane flux and 236 analyzed with a gas chromatograph (Agilent Technologies, 7820A) equipped with a 237 PORAPAK Q80/100 column using TCD and FID detectors. The $J$ and $\alpha$ values are the 238 averages of more than two runs of $8 \mathrm{~h}$ to ensure the accuracy of the results. Every 239 membrane sample was analysed twice which means that the membrane tested as a 240 function of temperature was stable for at least ca. $60 \mathrm{~h}$.

241 Pervaporation separation factor (PSI) was also calculated as the separation ability of the 242 membranes. PSI is typically expressed as a product of total permeate flux and separation 243 factor, as Eq. (5) describes:

\section{Results and discussion}

\subsection{Membrane characterization}

248 The glass transition temperature $\left(T_{g}\right)$ for cross-linked PVA membranes was around $24995.6 \pm 2.8^{\circ} \mathrm{C}$, as it is displayed in Table 1. This value is included in the range $\left(69-110^{\circ} \mathrm{C}\right)$ 250 that was reported by previous studies [7,15,22]. Furthermore, the MMMs exhibited higher $251 T_{g}$ values (around $104-110^{\circ} \mathrm{C}$ ) than the pristine PVA membranes. It is well documented 252 that the incorporation of inorganic fillers into a polymer may cause an increase in $T_{g}$ if 253 there are strong attractive forces between the filler surface and the polymer. Particularly, 254 this change could be attributed to the hydrogen bonding among multiple oxygen 
containing functional groups of the GO sheets and the PVA chains rich in alcohol groups

256 [22]. Figure S1 (supplementary material) shows the TGA curves that can be related to 257 the thermal degradation and stability of the GO and the cross-linked PVA-GO 258 membranes. The first weight loss visible in GO sheets start around $55{ }^{\circ} \mathrm{C}$. Such 259 degradation is attributed to the loss of the water molecules that were retained in its 260 structure and it accounts for $17.7 \%$ by weight of the total sample that was analyzed. The 261 second weight loss took place at $200{ }^{\circ} \mathrm{C}$, and was presumably due to pyrolysis of the 262 labile oxygen-containing functional groups yielding $\mathrm{CO}, \mathrm{CO}_{2}$ and steam [23]. Moreover, it 263 is quite possible that the weight loss may come from the combustion of carbon. Therefore, 264 the decomposition of GO can be accompanied by a vigorous expansion of the gas 265 resulting from the rapid thermal expansion of the material [24] in agreement with the 266 abrupt step observed. This weight loss corresponds to $72.4 \%$ by weight of the total 267 material. The last weight loss took place at $550^{\circ} \mathrm{C}$ and it is due to the combustion process. 268 As observed, once dehydrated at ca. $100^{\circ} \mathrm{C}$, the pristine cross-linked PVA membrane 269 has its degradation step between $300-510{ }^{\circ} \mathrm{C}$, which corresponds to the complete 270 decomposition of the PVA (weight loss around 85\%). Similarly, its MMM-GO membranes 271 presented a first gradual weight-loss (15-19\%) starting at $55^{\circ} \mathrm{C}$, which is more remarkable 272 at the high GO loading. This is probably attributed to the loss of the guest water molecules 273 that could be retained in the GO structure, e.g. water molecules trapped in graphitic 274 domains of GO [25], as well as the water retained in the possible interfacial voids between 275 the GO and PVA matrix. Moreover, there was a weight-loss (between $175-275^{\circ} \mathrm{C}$ ) for the 276 MMMs, which was more pronounced as the filler loading increased. This can be related 
277 to the GO decomposition. Moreover, the MMMs also presented their degradation step 278 starting at $300^{\circ} \mathrm{C}$ up to $500^{\circ} \mathrm{C}$. This represents a weight-loss of about $80-85 \%$.

Table 1. $T_{g}$ and contact angle (CA) values of the pure cross-linked PVA membranes and 281 its MMMs-GO.

Figure 2 shows the surface and cross-section FESEM images of the membranes. In case 284 of a surface view, the pure cross-linked PVA membrane (see Figure 2a) showed a 285 uniform and smooth surface characteristic without signs of plastic deformation, which is 286 common for cross-linked PVA dense membranes [26]. Whereas the MMMs-GO 287 containing 1 and 2 wt.\% slightly lost the uniform surface by increasing the GO content 288 (see Figure 2c\&e), which could be attributable to the exposure of GO flakes on 289 membrane surface.

290 In cross-sectional view, pure cross-linked PVA membrane presents a typical crater-like 291 pattern which has been already reported by Amirilargani and Sadatnia (2014). Typically,

292 this crater-like pattern is generated during deformation by the freeze fracture of polymeric 293 membranes [27]. Moreover, this pure PVA membrane exhibits a skin layer, or better294 known as "top layer", of about $2.6 \mu \mathrm{m}$ in thickness. This dense surface layer commonly 295 appears by an extremely short-term reduction of solvent concentration on the surface 296 contacting the air. Such layer tended to be dissipated by incorporating the GO in MMMs.

297 The cross-sectional view also displayed an increase in roughness with an increment in 298 GO loading. When GO concentration reached 2 wt. \% the structure showed a tendency of 299 assembling to the membrane surface (see Figure 2f), similar to a segregation 
phenomenon which has been reported during the GO embedding into chitosan [28]. In

301 fact, in case of cross-linked PVA- GO 2 wt.\% membrane, Figure $\mathbf{S 2}$ shows the XRD

302

303

304

305

306

307

308

309

310

311

312

313

314

315

316

317

318

319

320

321

322

patterns obtained from its top (with the mentioned skin layer) and bottom layers of the dense membrane, where it can be seen that the presence of GO shifted slightly the PVA signal. This, more evident at the highest GO loading, is in agreement with the floating suffered by the GO sheets during MMM preparation that tend to be accumulated on the top of the MMM. Furthermore, the GO seems to be parallelly deposited to the membrane surface, this pattern has been observed when embedding into polyimide [29] and PVDF [30]. This particular orientation can be related to the remaining functional groups on the edges of GO on every side. Therefore, it is quite probable that GO sheets would have this preferred alignment over the membrane [22,30].

Figure 2. Surface and cross-section FESEM images of pure cross-linked PVA $(a, b)$ and MMMs at 1 wt.\% (c, d) and 2 wt. \% (e, f) GO content, respectively.

The morphology of GO flakes was investigated by TEM. Figure 3a shows a single GO flake with sheet-like multilayer structure, typical for GO, with approximately $200 \mathrm{~nm}$ in diameter and evident high aspect ratio. GO sheets are regularly distributed in cross-linked PVA-GO 1 wt.\% membrane (see Figure $\mathbf{3 b}$ ) that is in agreement with the homogeneous color of the membrane shown in Figure 1. Figure 3c presents TEM images of GO sheets in cross-linked PVA-GO 1 wt. \% membrane with an angle of observation of $-26^{\circ}, 0^{\circ}$ and $27^{\circ}$, respectively. The target of measuring at different angles was to confirm that the material possesses high aspect ratio and sheet-like multilayer structure. This is not so 
327 membranes [31,32].

328 Continuing with the TEM observation, as can be seen in the inset of Figure $\mathbf{3 d}$ the 329 330

evident in the dark GO agglomerates of Figure 3c. However, near such GO agglomerates thin GO flakes are envisaged, and their form changes with the angle producing "shadows" of different shape, size and greyscale due to their different alignment to the electron beam. This is usually considered as a proof of lamellar nature of the filler in these kind of electron diffraction pattern of particles embedded in the membrane corresponds to an ordered material with three reticular planes parallel to the electron beam. In fact, six spots can be observed in the reciprocal space that correspond to planes (1 00$),\left(\begin{array}{ll}1 & -1\end{array}\right)$ and (0 10 ) of graphene oxide. The d-spacings of such planes have been measured, resulting in a mean value of $0.20 \pm 0.01 \mathrm{~nm}$. The side of the hexagons is ca. $0.12 \mathrm{~nm}$, which is consistent with the length of the covalent bonds between carbon atoms in graphene oxide [33]. The inset of Figure $3 e$ shows a GO flake in the MMM and its reciprocal space (inset). Two spots can be observed that correspond to planes $\left(\begin{array}{ll}0 & 0\end{array}\right)$, with a d-spacing equal to $0.38 \pm 0.00 \mathrm{~nm}$. Moreover, the d-spacing between $\left(\begin{array}{lll}0 & 0 & 1\end{array}\right)$ reticular planes is $0.76 \mathrm{~nm}$, similar to that reported by Strankowski et al. [34]. Finally, in the images of the Fourier transform (insets of Figure $3 d$ and $3 e$ ), the bright circles are due to a destructive interference of diffracted electrons, indicating the presence of an amorphous material, in this case the PVA matrix.

Figure 3. TEM images of GO flakes (a), distribution of GO flakes in MMM (b), GO flake in MMM observed at different angles $-26^{\circ}, 0^{\circ}$ and $27^{\circ}$ (c), GO flakes in MMM and Fourier transform of the selected zone. 
347 The X-ray diffractogram of the $G O$ exhibited a sharp diffraction peak at $2 \cdot \theta=11.8^{\circ}$ 348 corresponding to d-spacing of $0.75 \mathrm{~nm}$, that agrees with the reported values [35] (see 349 Figure 4). Furthermore, this value is in good agreement with that calculated by TEM. The 350 shift of the GO peak position from its primary material (graphite) is due to the presence 351 of oxygen-containing functional groups that intercalate into the space between individual 352 graphene sheets provoking an increase of the d-spacing [36]. Moreover, the pure PVA 353 displays a strong diffraction peak at $2 \cdot \theta=19.6^{\circ}$, which was less intense after the cross354 linking procedure. Furthermore, some peaks at $12^{\circ}$ and $22^{\circ}$ in PVA were identified. These 355 peaks disappeared later, what is normally attributed to the reduction of crystallinity of PVA 356 membranes by the cross-linking [7]. The cross-linked PVA-GO MMMs also exhibited 357 similar features with a slight change compared to the pure one. No peak corresponding 358 to GO sheets was discernible, which can be due to the low loading of the material in the 359 MMMs, in agreement with analogous GO-PVA reinforced composites [22]. Moreover, the 360 absence of diffraction peaks related to the GO interlayer spacing may also be due to the 361 lack of preferential orientation of the GO flakes [37]. However, the GO loading could be 362 enough to modify the spacing of polymer chains [7].

Figure 4. XRD patterns of the pure PVA, pure GO, cross-linked PVA and its MMMs-GO. 365

Regarding the FTIR spectra, Figure 5 exhibits standard absorption peaks for the PVA 367 polymer. The presence of characteristic absorption peaks at $\sim 1100 \mathrm{~cm}^{-1}$ and $\sim 1150 \mathrm{~cm}^{-1}$ can be seen. A modest change was noticed a distinct and broad $-\mathrm{OH}$ stretch at $\sim 3200$ 
$\mathrm{cm}^{-1}$ that appeared due to the cross-linking procedure using glutaraldehyde. Such change can be attributed to the presence of alcohols for intermolecular hydrogen bonds in the polymer. Moreover, as reported by Kashyap et al. [22], the PVA-GO MMMs exhibited

372 similar features with a slight shift of the peak to lower wavenumbers, displaying strong 373 interfacial interactions between the polymer matrix and GO.

Figure 5. FTIR spectroscopy of the GO, glutaraldehyde, pristine PVA, cross-linked PVA and the PVA-GO 1 wt.\% samples.

The measured water contact angle value for cross-linked PVA membrane was around $69.6^{\circ} \pm 0.5^{\circ}$, as it is reported in Table 1 . The obtained value which is within the range of $57^{\circ}-77^{\circ}$ is in agreement with that reported by several authors $[26,38]$. The hydrophilicity depends on the type of cross-linker used and the consumption of -OH groups during the cross-linking $[26,38]$. However, the hydrophilic nature was still confirmed in the cross383 linked membranes. On the other hand, the cross-linked PVA displayed an enhanced hydrophilicity by embedding GO into its matrix, e.g. up to $58.4^{\circ} \pm 0.5^{\circ}$ for the MMMs-GO 2 wt.\%. Generally, the water contact angle decreased with an increase of GO content. This is related to the abundant oxygen-containing functional groups on the wrinkled GO sheets 387 [28]. In addition, the enhancement of water contact angle of MMMs was leveled off when 388 GO content was higher than 1 wt. \%, whereas it did not show strong change in case of 2 389 wt.\%. GO caused a decrease of water contact angle also in other MMMs based on 390 chitosan [28,39] and polyimides [40]. In theory, the wettability of a membrane is directly

391 associated with the water adsorption rate on the membrane surface, which is highly 

important in PV since it is considered as the first step of water transport through the membrane based on the solution-diffusion mass transfer mechanism.

394 The uptake of membranes was carried out from their contact with 10/90 wt.\% water395 ethanol solution (the same concentration used in the PV experiments). The calculated 396 uptake results are depicted in Figure 6. It can be seen that the uptake decreased with an 397 increase of the GO content. This tendency has been reported during the incorporation of 398 GO into hydrophilic chitosan membranes [28]. Basically, the decrease in uptake is related 399 to the strong GO-polymer interactions which, besides reducing the availability of 400 hydrophilic groups, could restrict the mobility of PVA chains and decrease even more the 401 free volume of the cross-linked PVA. GO has demonstrated, as multi-walled carbon 402 nanotubes [15], to suppress the swelling degree of these PVA membranes. Therefore, 403 GO provides better stability in the cross-linked PVA against the swelling phenomenon. 404 Finally, it is worth to mention that the cross-linking made the membrane more resistant to 405 the ethanol-water mixture that would otherwise dissolve.

Figure 6. Uptake of the cross-linked PVA and MMMs-GO membranes at 10:90 wt.\% 408 water-ethanol (at $\left.40^{\circ} \mathrm{C}\right)$.

410 As can be seen from Figure 7, the addition of GO has a relevant effect on the mechanical 411 properties of the pristine cross-linked PVA membranes. The incorporation of GO led to a 412 general improvement of the mechanical behavior of the pristine membranes in terms of 413 Young's modulus, tensile strength and elongation at break. The tensile strength value, for 414 instance, displayed in Figure 7c, increased from $27 \mathrm{~N} \cdot \mathrm{mm}^{-2}$ for the pristine PVA 
415 membrane up to $43 \mathrm{~N} \cdot \mathrm{mm}^{-2}$ for the membrane loaded with $0.5 \mathrm{wt} \% \mathrm{GO}$ with an increase 416 of tensile strength of about $60 \%$. The increase was particularly pronounced for lower GO 417 loadings (0.5 and 1 wt.\%). An improvement of Young's modulus was also observed for 418 all the MMMs by adding GO (Figure 7a) in particular at the lowest filler content, e.g. a $419134 \%$ increase was observed in comparison to the pristine one. The elongation at break, 420 after an initial increase at $0.5 \mathrm{wt} \% \mathrm{GO}$ (from $103 \%$ to $154 \%$ ) tended to decrease at the 421 highest GO concentration (down to $32 \%$ ) (Figure $7 b$ ). This could be due to the interaction 422 of GO with the membrane matrix that hinders the movement of the polymer chains at high 423 filler concentrations [41], in line with the above discussed increases of $T_{g}$ values (See 424 Table 1). This trend of the change of mechanical properties is similar to that observed by 425 Zhao et al. [41], where PVA membranes were loaded with different concentrations of 426 graphene nanosheets. They observed an increase in the tensile strength from $17 \mathrm{~N} \cdot \mathrm{mm}^{-}$ 4272 for the pristine PVA membrane to $42 \mathrm{~N} \cdot \mathrm{mm}^{-2}$ for the membranes loaded with $1.8 \mathrm{vol} \%$ 428 of graphene nanosheets. The Young's modulus also increased from $1000 \mathrm{~N} \cdot \mathrm{mm}^{-2}$ to 429 about $10000 \mathrm{~N} \cdot \mathrm{mm}^{-2}$ when graphene (1.8 vol\%) was added to the PVA. The authors 430 explained these results stating that there exists a critical point of graphene nanosheets 431 loading (called mechanical percolation) [22], where beyond this concentration there is no 432 improvement in the membrane mechanical properties due to the stacking of nanosheets. 433 Hence, by diminishing this concentration (which they found at $1.8 \mathrm{vol} \%$ for graphene 434 sheets), an improvement in the membrane mechanical properties can be obtained due to 435 the better dispersion of the filler in the polymer matrix. In this work, the critical point can 436 be identified at the 1 wt.\% GO content. As can be observed in Figure 7a\&c, the 437 membrane mechanical properties were greatly improved below this value. A similar trend 
was also observed and reported by Kashyap et al. [22] during the reinforcement of PVA polymer matrices, where at low GO concentrations ( $0.3 \mathrm{wt} . \%$ only) the mechanical properties of PVA membranes were enhanced. This improvement was attributed to the uniform dispersion of the $\mathrm{GO}$ in the membrane and to the strong hydrogen bonding interfacial interaction between the filler and membrane matrix.

Figure 7. Mechanical properties of cross-linked PVA membrane and MMMs-GO before and after exposure to water-ethanol (10:90 wt. \%) mixture.

Moreover, the mechanical properties were also measured for the pristine PVA membrane and its MMMs after soaking them in a water-ethanol solution (10:90 wt.\%) during $24 \mathrm{~h}$. A general decrease of the mechanical properties in terms of Young's modulus and tensile strength was observed after exposure of the membranes to the solution. The mechanical properties of the membranes, therefore, may be subjected to a plasticization effect due to the hydrogen bonds formation between polar molecules (i.e. from ethanol and water) and PVA polymer. As a consequence, in the swollen state, the chain-chain polymer interactions decreased resulting in a contraction of the membranes. Commonly, the exposure to the water-ethanol solution led to a swelling phenomenon in membranes of poly(lactic acid)/poly(vinyl pyrrolidone) [42]. On the contrary, the elongation at break of the MMMs containing 0.5 and $1 \mathrm{wt} \%$ GO was slightly enhanced after soaking (Figure $7 b)$. 


\subsection{Pervaporation tests}

3.2.1. Effect of $\mathrm{GO}$ loading and temperature on PV performance

463 Figure 8 displays the effect on GO content of the total permeate flux during the PV 464 performance as a function of the operating temperature (data available in supplementary 465 material, Table S1). Essentially, an increment in the total permeation rate was observed 466 with a double increase of GO loading. This tendency is commonly observed during the 467 incorporation of the inorganic materials into polymer membranes, which may be a result 468 of the free volume increase as well as the possible interfacial selective gaps between GO 469 sheets and PVA matrix, while the highly hydrophilic nature of the filler can also produce 470 a raise in the permeation rates by preferential adsorption of the more polar compound 471 (water). Moreover, an escalation on the total permeation was observed with temperature 472 increase $\left(40-70^{\circ} \mathrm{C}\right)$. In theory, the polymer chains tend to be more flexible at higher 473 temperatures promoting the sorption ability of the components, leading to the increase of 474 permeating compounds through the intermolecular distances of the polymeric membrane. 475 Also, the viscosity of the liquid feed diminishes with temperature favoring the permeate 476 transport through the membrane.

478 Figure 8. Total permeate flux as a function of the GO loading at different operating 479 temperatures (10:90 wt.\% water-ethanol). The curves are only guides to the eye.

481 The effect of the temperature on total permeate flux can be analyzed by using the so482 called Arrhenius relationship (Eq. 5) [43], as follows: 


$$
J=J_{0} \cdot \exp \left(-\frac{E_{a}}{R \cdot T}\right)
$$

484 Where $J_{o}$ is the pre-exponential factor, $E_{a}$ is the apparent activation energy for permeation 485 (for the overall mixture and each component) and $R \cdot T$ is the common energy term. The 486 linearization of the Eq. (5) through logarithmic laws leads to the plot of Figure S3, which 487 displays the total fluxes as a function of the reciprocal of temperature at azeotropic 488 conditions. The figure confirms that an Arrhenius relationship exists between total fluxes 489 and operating temperature. i.e. the total flux tends to raise with an increase of the 490 temperature. Furthermore, the apparent activation energy $\left(E_{a}\right)$, which can be calculated 491 as the slope of the curve (Figure S3), and using the Eq. (5), can provide an outlook on 492 the relationship between the total flux and the GO content. From Table 2, it can be seen 493 that the $E_{a}$ values for total flux gradually decrease with an increase of filler loading, e.g. $4947.0 \mathrm{~kJ} / \mathrm{mol}$ in the pristine PVA membranes to $1.9 \mathrm{~kJ} / \mathrm{mol}$ in the MMMs-2 wt.\% GO. At this 495 point, the $E_{a}$ decrease towards water was more influenced than that for ethanol in the 496 range of handled temperature $\left(40-70^{\circ} \mathrm{C}\right)$. Importantly, the PV process in the handled 497 temperature affects mainly the permeation rate of water, and does influence minimally 498 the ethanol permeation. While the presence of GO contributes to the reduction of the 499 energy needed for the components to permeate across the membranes [44]; similar 500 behavior was recently reported by Qian et al. [28] during the PV desalination of water 501 through chitosan-GO membranes. 
Table 2. Apparent activation energies for total permeate, water and ethanol partial fluxes of the PVA membrane and its MMMs at different GO loadings (Data obtained from Figures S3-S5).

Regarding the separation factor (water selectivity), see Figure 9, a decrease as a function of the temperature for pure cross-linked PVA membrane as well as its MMMs has been observed. Certainly, the decrease of separation factor in the MMMs might be due to the combined effect of several factors, such as characteristics of GO (e.g. GO structure and the influence of its preparation procedure), polymer properties, the effect of the crosslinking procedure on the adsorption capacity of the polymer, and of course, the operating temperature. In principle, high separation factors and lower permeation rates were obtained at the lowest temperatures for all membranes. Based on the free volume theory, the thermal motion of polymer chains in the amorphous regions results in free volume. As temperature increases, the frequency and amplitude of the chain jumping (i.e. thermal agitation) increase and the resulting free volume becomes larger [45]. Therefore, this thermal motion of the polymeric chains may facilitate the diffusion of larger molecules (like ethanol) through the membrane causing a decrease in separation factor, in agreement with the fact that activation energy values for ethanol are always larger than those of water (see Table 2). The absence of negative values for the activation energy data reveals that the permeation of the species presented in these MMMs is less governed by the adsorption [44]; indeed, polymer cross-linking strongly tends to affect the membrane adsorption, e.g. in PVA [46]. Moreover, the diffusion of a binary liquid mixture is typically characterized by self- and cross (coupled) - plasticization of a permeant. At this point, 

self-plasticization of permeants means that the flux of one component is affected only by

527 its own sorption amount.

528 The effect of crystallinity of the PVA membrane also plays an important role in the 529 transport of species. The crystalline regions act as giant cross-linking regions with respect 530 to chains that are partially embedded in several crystallites. The swelling and diffusion 531 are reduced in comparison to those in the totally amorphous polymer. The restriction of 532 crosslinking regions on segmental mobility makes the diffusion process more difficult and 533 dependent on the shape and size of the molecules [47]. In this way, the crystallinity of the 534 PVA can be strongly affected by the cross-linking procedure, as well as the incorporation 535 of inorganic materials into its matrix [15].

536 It is worth mentioning, as Figure 9 displays, that the separation factor at any of the 537 temperatures did not follow a continuous decreasing trend. From the strict point of view 538 in case of separation factor values (Table S2 and Figure 9), the first addition of GO (0.5 539 wt.\%) was not enough to compensate the distortion in the PVA chains that caused the 540 formation of non- selective pores (but hydrophilic), and it was necessary to double the 541 filler amount (1 wt.\%) to compensate in part the loss of selectivity. In other words, at 1 542 wt.\% GO, the concentration of sheets in the MMMs is high enough as to exert an 543 additional barrier effect to bulkier ethanol molecules (decreasing the ethanol PV flux 544 through the membrane, see Figure 10) and thus to recover part of the separation factor 545 of the bare cross-linked PVA membrane. Nevertheless, the MMMs-2 wt.\% GO had an 546 excess of filler and the separation factor worsened in agreement with the loss of 547 mechanical properties seen above. 
Figure 9. Separation factor as a function of the GO loading at different operating

550 temperatures (10: 90 wt.\% water-ethanol). The lines are only guides to the eye.

551

552 Figure 10. Water and ethanol partial fluxes as a function of the GO loading at different 553 operating temperatures (10:90 wt.\% water-ethanol). The curves are only guides to the 554 eye.

556 Definitely, the modification of PVA with GO filler favors the preferential transport of water.

557 This is due to the fact that GO laminates simultaneously have oxidized (proper GO, 558 hydrophilic) and non-oxidized (graphene, hydrophobic) regions. The non-oxidized regions 559 of graphene sheets possess a d-spacing of ca. $5 \AA$ [48], which is enough to host a 560 monolayer of water (kinetic diameter=2.68 $\AA$ ). It has been speculated that these empty 561 spaces form a network of pristine-graphene capillaries within GO laminates [49], which 562 would facilitate the water transport. Figure 11 shows a scheme of the possible water 563 permeation mechanism involving GO species. It has been reported that, even when the 564 mixture of water and other compounds (e.g. gases and liquids) was fed, the water 565 permeation rate was at least five orders of magnitude higher than that of the other 566 components $[49,50]$. In fact, using equilibrium molecular dynamics simulations, it has 567 been stated that water can easily flow through graphene nano-channels (e.g., the non568 oxidized region of GO) [51]. Importantly, taking into account that graphene sheets 569 possess a d-spacing of ca. $5 \AA$, this d-spacing is still slightly larger than the kinetic 570 diameter of the ethanol molecules $(4.5 \AA)$ [15], which may allow them passing through. 571 However, interestingly, this characteristic d-spacing of GO can be enlarged in the 
572 presence of water. For instance, the interlayer spacing can vary from $\approx 6.4$ to $9.8 \AA$ with

573 relative humidity changes from 0 to $100 \%$ [37]. Thereby, water and ethanol molecules

574 can surely pass through the channels of GO; however, according to our findings and the

575 ones in literature, GO is still displaying a preferential transport of water [25].

576

577

578 Figure 11. Schematic drawing of the possible water permeation mechanism through GO 579 laminates. Inspired by Nair et al. (2012).

580

581 To date, it is clear that the water transport mechanism in the GO laminar structure is still 582 not well understood and established, particularly in pervaporation which involves selective 583 permeation and evaporation [25]. Especially, when using GO membranes, the separation 584 of water from organics is mainly related to preferential adsorption of water in GO [52], 585 such preferential adsorption has been attributed to the large amount of hydrophilic 586 functional groups in GO and the low water condensation partial pressure according to the 587 fine laminar structure. Herein, solution-diffusion (also known as adsorption-diffusion) 588 model has been widely sought to explain such phenomenon. However, while the 589 preferential adsorption of water has been repeatedly confirmed by many researchers, the 590 diffusion of water in GO membranes is not much discussed in terms of adsorption591 diffusion model [52,53]. This description addressing the adsorption phenomenon 592 (governed by concentration gradient) compromise the hypothesis provided by Nair et al. 593 [49], in which the explanation about the transport of water in the interlayer space follows 594 a pore flow model (governed by pressure difference). In this sense, Chong et al. [25] 
595 analyzed the water transport through GO membranes using two different modes: 596 pressure-driven permeation and pervaporation. Basically, the authors stated that pure 597 water flux is 1-2 orders of magnitude higher in PV due to the large capillary pressure 598 induced by evaporation.

599 Finally, the decrease in separation efficiency can also be affected by the synthesis of GO. 600 According to Hung et al. [53], it is extremely challenging to form highly ordered and 601 precise GO laminates. It has been reported that the repulsive electrostatic interactions 602 produced by negatively charged carboxyl groups might create some out-of-order 603 accumulation (i.e. wrinkles). Also, a large number of nonselective defects (basic plane 604 holes) derived from the strong oxidization conditions applied to obtain GO may penalize 605 the membrane separation performance [50].

606

607

\subsubsection{Comparison of cross-linked PVA-GO MMMs with other studies}

608 The performance of polymeric and MMMs for any water-organic separation, like water609 ethanol, through PV, depends directly on: i) the polymer characteristics (e.g. material 610 type, nature, structure, thickness); the filler features (e.g. shape, size, 611 hydrophilicity/hydrophobicity, morphology); iii) the physico-chemical properties and 612 concentration of the compounds in the mixture to be separated; and iv) the operating 613 conditions (e.g. temperature, vacuum pressure, feed flow rate) [54,55]. This makes 614 difficult to fairly compare PV data with works where different conditions have been 615 applied, bearing also in mind that our work is the first one dealing with the use of cross616 linked PVA-GO membranes for water-ethanol separation by PV. Having said that, Table 
6173 compares water-ethanol PV performances of a number of MMMs filled with 618 carbonaceous materials, zeolites, MOFs and several porous and non-porous oxides.

Table 3. Comparison of the cross-linked PVA-GO MMMs performance with other studies

621 for the dehydration of ethanol.

622

623 It is a challenging task selecting the best performance of cross-linked PVA-GO MMMs 624 obtained in the current work in terms of permeate flux and separation factor, because 625 cross-linked PVA membrane itself possesses high separation efficiencies $(\alpha=163-518$ 626 with total PV fluxes $=0.079-0.131 \mathrm{~kg} \cdot \mathrm{m}^{-2} \cdot \mathrm{h}^{-1}$, see Tables S1 and S2 and Figures 8 and 9) depending on handled temperature. Considering the MMMs containing 1 wt. \% GO as 628 the optimum loading ( $\alpha=88.2-263$ with total PV fluxes $=0.137-0.162 \mathrm{~kg} \cdot \mathrm{m}^{-2} \cdot \mathrm{h}^{-1}$, see Tables S1 and S2 and Figures 8 and 9), their separation factors are higher than those of other 630 membranes based on chitosan-H-ZSM-5 [13], chitosan-TiO2 [56], cross-linked PVA-ZIF631 8- $\mathrm{NH}_{2}[16]$ and polyimide-MSS-1 [6]; but lower than those corresponding to membranes of 632 cross-linked sodium alginate-beta zeolite [11], polyimide-ZIF-8 [6], cross-linked sodium 633 alginate-zeolite [57], PVA-MWCNT [15], and cross-linked chitosan-silica [58].

634 Moreover, the pristine cross-linked PVA displays relatively acceptable total permeate flux $635\left(\mathrm{~J}=0.079-0.131 \mathrm{~kg} \cdot \mathrm{m}^{-2} \cdot \mathrm{h}^{-1}\right)$, while its MMMs containing $2 \mathrm{wt} . \%$ GO have shown the highest 636 permeate flux values of about $0.185 \mathrm{~kg} \cdot \mathrm{m}^{-2} \cdot \mathrm{h}^{-1}\left(\right.$ at $\left.70^{\circ} \mathrm{C}\right)$. Such fluxes are higher than the 637 reported ones using cross-linked sodium alginate-beta zeolite [11], PVA-MWCNT [15], 638 and cross-linked sodium alginate-zeolite [57]; however, other MMMs provided even 639 higher permeation fluxes than the ones presented in this study, such as chitosan-H-ZSM- 
5 [13], polyimide-ZIF-8 [6], chitosan- $\mathrm{TiO}_{2}$ [56], polyimide-MSS-1 [6] and cross-linked

641 chitosan-silica [58]. It is important to highlight that the current PV flux enhancements 642 obtained with the cross-linked PVA-GO MMMs that enlarge permeate flux (mainly 643 towards water) were obtained by incorporating a small amount of GO filler, which is much 644 lower compared to previous studies. Finally, regardless of the amount of GO used for the 645 preparation of these membranes, the right choice of the MMM will depend on the final 646 purpose (high productivity or high separation efficiency), as well as the feasibility of the 647 process considering primordially its operating conditions, e.g. temperature, that indeed 648 influences on the PV performance.

649 When dealing with the separation performance of PV membranes, it is useful to compare 650 their separation ability by means of PSI (see Table 3). It can be seen that the PVA-GO 651 MMMs (1 wt.\%) display better PSI values in comparison to some MMMs based on 652 chitosan-H-ZSM-5, cross-linked PVA-ZIF-8-NH $\mathrm{NH}_{2}$, and some commercial membranes 653 (PVA composites). However, there are still some other membranes that present superior 654 performances, such as cross-linked sodium alginate-zeolite beta, chitosan- $\mathrm{TiO}_{2}$, 655 polyimide-MSS-1, cross-linked chitosan-silica and polyimide-ZIF-8. Finally, permeance 656 and selectivity are the best way of reporting pervaporation results when a fair comparison 657 of different studies is needed (considering experiments at different feed concentrations, 658 feed temperatures and permeate pressures) [55]. Permeance should be independent on 659 the driving force and should just describe the system membrane/permeating component. 660 In this way, the PV data for all MMMs are also provided for the readers (data available in 661 supplementary material; Table S5). 
663

664 665

666

667

668

669

670

671

672

673

674

675

676

677

678

679

680

681

682

683

684

685

\section{Conclusions}

Cross-linked-PVA membranes containing GO have been successfully tested for the PV separation of the water-ethanol azeotropic mixture. The effect of operating temperature has been evaluated. The best performance of cross-linked PVA-GO membranes has been provided by the one containing $1 \mathrm{wt} . \%$ filler, displaying an acceptable separation factor $\left(263\right.$, at $40^{\circ} \mathrm{C}$ ) with a high permeate total flux of about $0.137 \mathrm{~kg} \cdot \mathrm{m}^{-2} \cdot \mathrm{h}^{-1}$ (in which $0.133 \mathrm{~kg} \cdot \mathrm{m}^{-2} \cdot \mathrm{h}^{-1}$ corresponds to water). At this point, these MMMs, having only $1 \mathrm{wt} . \%$ $\mathrm{GO}$, have demonstrated the enhancement of the permeation performance of pristine cross-linked PVA membranes, by over $75 \%$ compared to their original permeation rates. Of course, higher permeate fluxes can be obtained by increasing $i$ ) the temperature, since the total, water and ethanol fluxes have shown a positive temperature dependence; and ii) filler loading, e.g. 2 wt.\% GO. Based on the obtained results, it is possible to conclude that these PVA MMMs membranes have a promising potential to be used in PV for the dehydration of ethanol. Moreover, regarding the use of these MMMs in a "green" process, the incorporation of GO has satisfactorily enhanced the water transport of cross-linked PVA membranes, displaying losses on selectivity. However, the high water permeation fluxes could contribute to use less energy-requirement due to the less operating time may be needed to reach pure ethanol.

Finally, MMMs containing $1 \mathrm{wt} . \%$ GO have been considered as the optimum membranes with a good PV flux-separation factor ratio. This is in good agreement with better thermal $\left(T_{g}\right)$ and mechanical properties (Young' modulus, elongation at break and tensile strength) exhibited by these MMMs in comparison to those at 0.5 and $1 \mathrm{wt} . \% \mathrm{GO}$ loading. 
687 TGA curves of the cross-linked PVA membranes and its MMMs. XRD patterns of the 688 cross-linked PVA-GO 2 wt.\% membrane (top and bottom layer) and GO. Pervaporation 689 data (total flux, water flux, ethanol flux, separation factor, water permeance, ethanol 690 permeance, and selectivity) as a function of the GO loading at different operating 691 temperatures. Temperature dependence curves of total permeate, water and ethanol flux 692 by Arrhenius plot at different GO loadings.

693

694 Acknowledgments

695 R. Castro-Muñoz acknowledges the European Commission - Education, Audiovisual and 696 Culture Executive Agency (EACEA) for his $\mathrm{PhD}$ scholarship under the program: Erasmus 697 Mundus Doctorate in Membrane Engineering - EUDIME (FPA No 2011-0014, Edition V, 698 http:/eudime.unical.it). This work was partially supported by the Operational Program 699 Prague - Competitiveness (CZ.2.16/3.1.00/24501) and the "National Program of 700 Sustainability“ (NPU I LO1613) MSMT-43760/2015. Financial support from the Spanish 701 MINECO and FEDER (MAT2016-77290-R), the Aragón Government (T43-17R) and the 702 ESF is also gratefully acknowledged.

703

704 Note

705 The authors declare no conflict of interest.

706

707 References

708 [1] P. Luis, B. Van Der Bruggen, The driving force as key element to evaluate the 

(2015) 94-102.

711

712

[2] J. Crespo, C. Brazinha, Fundamentals of pervaporation, in: A. Basile, A. Figoli, M. Khayet (Eds.), Pervaporation, Vap. Permeat. Membr. Distill., Elsevier Ltd., Cambridge UK, 2015: pp. 1-17.

[3] P.T. Anastas, J.C. Warner, Green Chemistry: Theory and Practice, Oxford University Press, New York, 1998.

[4] Y.K. Ong, G.M. Shi, N.L. Le, Y.P. Tang, J. Zuo, S.P. Nunes, T.S. Chung, Recent membrane development for pervaporation processes, Prog. Polym. Sci. 57 (2016) $1-31$.

[5] R. Castro-Muñoz, F. Galiano, V. Fíla, E. Drioli, A. Figoli, Mixed matrix membranes ( MMMs ) for ethanol purification through pervaporation : current state of the art, Rev. Chem. Eng. https//doi.org/10.1515/revce-2017-0115. (2018).

[6] A. Kudasheva, S. Sorribas, B. Zornoza, C. Téllez, J. Coronas, Pervaporation of water/ethanol mixtures through polyimide based mixed matrix membranes containing ZIF-8, ordered mesoporous silica and ZIF-8-silica core-shell spheres, J. Chem. Technol. Biotechnol. 90 (2015) 669-677.

[7] M. Amirilargani, B. Sadatnia, Poly ( vinyl alcohol )/ zeolitic imidazolate frameworks ( ZIF-8 ) mixed matrix membranes for pervaporation dehydration of isopropanol, J. Memb. Sci. 469 (2014) 1-10.

[8] V. Van Hoof, C. Dotremont, A. Buekenhoudt, Performance of Mitsui NaA type zeolite membranes for the dehydration of organic solvents in comparison with commercial polymeric pervaporation membranes, Sep. Purif. Technol. 48 (2006) 
304-309.

733 [9] RFA, World Fuel Ethanol Production, Renew. Fuels Assoc. (2017). http://www.ethanolrfa.org/resources/industry/statistics/\#14540989964798715d404-e546 (accessed January 22, 2018).

[10] J.-H. Chang, J.-K. Yoo, S.-H. Ahn, K.-H. Lee, S.-M. Ko, Simulation of pervaporation process for ethanol dehydration by using pilot test results, Korean

[11] S.G. Adoor, L.S. Manjeshwar, S.D. Bhat, T.M. Aminabhavi, Aluminum-rich zeolite beta incorporated sodium alginate mixed matrix membranes for pervaporation dehydration and esterification of ethanol and acetic acid, J. Memb. Sci. 318 (2008) 233-246.

[12] G.M. Shi, T. Yang, T.S. Chung, Polybenzimidazole (PBI)/zeolitic imidazolate frameworks (ZIF-8) mixed matrix membranes for pervaporation dehydration of alcohols, J. Memb. Sci. 415-416 (2012) 577-586.

[13] H. Sun, L. Lu, X. Chen, Z. Jiang, Pervaporation dehydration of aqueous ethanol solution using H-ZSM-5 filled chitosan membranes, Sep. Purif. Technol. 58 (2008) 429-436.

[14] E. Okumuş, T. Gürkan, L. Yilmaz, Effect of fabrication and process parameters on the morphology and performance of a PAN-based zeolite-filled pervaporation membrane, J. Memb. Sci. 223 (2003) 23-38.

[15] J.H. Choi, J. Jegal, W.N. Kim, H.S. Choi, Incorporation of Multiwalled Carbon Nanotubes into Poly(vinyl alcohol) Membranes for Use in the Pervaporation of Water/Ethanol Mixtures, J. Appl. Polym. Sci. 111 (2008) 2186-2193. 
[16] Y. Zhang, H., Wang, Poly(vinyl alcohol)/ZIF-8 NH2 Mixed Matrix Membranes for Ethanol Dehydration via Pervaporation, AIChE J. 62 (2016) 1728-1739.

[17] V. Singh, D. Joung, L. Zhai, S. Das, S.I. Khondaker, S. Seal, Graphene based materials: Past, present and future, Prog. Mater. Sci. 56 (2011) 1178-1271.

[18] H.K. Dave, K. Nath, Graphene oxide incorporated novel polyvinyl alcohol composite membrane for pervaporative recovery of acetic acid from vinegar wastewater, J. Water Process Eng. 14 (2016) 124-134.

[19] N. Wang, S. Ji, J. Li, R. Zhang, G. Zhang, Poly(vinyl alcohol)-graphene oxide nanohybrid "pore-filling" membrane for pervaporation of toluene/n-heptane mixtures, J. Memb. Sci. 455 (2014) 113-120.

[20] S. Castarlenas, C. Téllez, J. Coronas, Gas separation with mixed matrix membranes obtained from MOF UiO-66-graphite oxide hybrids, J. Memb. Sci. 526 (2017) 205-211.

[21] W.S. Hummers, R.E. Offeman, Preparation of Graphitic Oxide, J. Am. Chem. Soc. 80 (1958) 1339.

[22] S. Kashyap, S.K. Pratihar, S.K. Behera, Strong and ductile graphene oxide reinforced PVA nanocomposites, J. Alloys Compd. 684 (2016) 254-260.

[23] G. Wang, Z. Yang, X. Li, C. Li, Synthesis of poly(aniline-co-o-anisidine)intercalated graphite oxide composite by delamination/reassembling method, Carbon N. Y. 43 (2005) 2564-2570.

[24] S. Stankovich, D.A. Dikin, R.D. Piner, K.A. Kohlhaas, A. Kleinhammes, Y. Jia, Y. Wu, S.B.T. Nguyen, R.S. Ruoff, Synthesis of graphene-based nanosheets via chemical reduction of exfoliated graphite oxide, Carbon N. Y. 45 (2007) 1558- 
1565.

779

780

781

782

783

784

785

786

787

788

789

790

791

792

793

794

795

796

797

798

799

800

[25] J.Y. Chong, B. Wang, K. Li, Water transport through graphene oxide membranes: the roles of driving forces, Chem. Commun. 54 (2018) 2554-2557.

[26] R. Zhang, X. Xu, B. Cao, P. Li, Fabrication of high-performance PVA / PAN composite pervaporation membranes crosslinked by PMDA for wastewater desalination, Pet. Sci. 15 (2018) 146-156.

[27] F. Dorosti, M. Omidkhah, R. Abedini, Fabrication and characterization of Matrimid/MIL-53 mixed matrix membrane for $\mathrm{CO} 2 / \mathrm{CH} 4$ separation, Chem. Eng. Res. Des. 92 (2014) 2439-2448.

[28] X. Qian, N. Li, Q. Wang, S. Ji, Chitosan/graphene oxide mixed matrix membrane with enhanced water permeability for high-salinity water desalination by pervaporation, Desalination. 438 (2018) 83-96.

[29] X. Li, L. Ma, H. Zhang, S. Wang, Z. Jiang, R. Guo, H. Wu, X.Z. Cao, J. Yang, B. Wang, Synergistic effect of combining carbon nanotubes and graphene oxide in mixed matrix membranes for efficient CO2separation, J. Memb. Sci. 479 (2015) $1-10$.

[30] E.A. Feijani, A. Tavassoli, H. Mahdavi, H. Molavi, Effective gas separation through graphene oxide containing mixed matrix membranes, J. Appl. Polym. Sci. $135(2018) 1-11$.

[31] C. Rubio, C. Casado, P. Gorgojo, F. Etayo, S. Uriel, C. Téllez, J. Coronas, Exfoliated Titanosilicate Material UZAR-S1 Obtained from JDF-L1, Eur. J. Inorg. Chem. 1 (2010) 159-163.

[32] S. Choi, J. Coronas, E. Jordan, W. Oh, S. Nair, F. Onorato, D.F. Shantz, M. 
Tsapatsis, Layered Silicates by Swelling of AMH-3 and Nanocomposite Membranes **, Angew. Chem. Int. Ed. 47 (2008) 552-555.

[33] N.R. Wilson, P.A. Pandey, R. Beanland, R.J. Young, I.A. Kinloch, L. Gong, Z. Liu, Ḱ.K. Suenaga, Ḱ.J.P. Rourke, S.J. York, J. Sloan, Graphene Oxide : Structural Analysis and Application as a Highly Transparent Support for Electron Microscopy, ACS Nano. 3 (2009) 2547-2556.

[34] M.B. Strankowski, W.B. Damian, A. Piszczyk, J. Strankowska, Polyurethane Nanocomposites Containing Reduced Graphene Oxide, FTIR, Raman, and XRD Studies, J. Spectrosc. 2016 (2016) 1-6.

[35] K. Krishnamoorthy, M. Veerapandian, K. Yun, S.J. Kim, The chemical and structural analysis of graphene oxide with different degrees of oxidation, Carbon N. Y. 53 (2013) 38-49.

[36] D.R. Dreyer, S. Park, C.W. Bielawski, R.S. Ruoff, The chemistry of Graphite oxide, Chem. Soc. Rev. 39 (2010) 228-240.

[37] J. Abraham, K.S. Vasu, C.D. Williams, K. Gopinadhan, Y. Su, C.T. Cherian, J. Dix, E. Prestat, S.J. Haigh, I. V Grigorieva, P. Carbone, A.K. Geim, R.R. Nair, Tunable sieving of ions using graphene oxide membranes, Nat. Nanotechnol. (2017) 1-6.

[38] R. Zhang, B. Liang, T. Qu, B. Cao, P. Li, High-performance sulfosuccinic acid cross-linked PVA composite pervaporation membrane for desalination, Environ. Technol. (United Kingdom). 3330 (2017) 1-9.

[39] S.P. Dharupaneedi, R. V. Anjanapura, J.M. Han, T.M. Aminabhavi, Functionalized graphene sheets embedded in chitosan nanocomposite membranes for ethanol 
and isopropanol dehydration via pervaporation, Ind. Eng. Chem. Res. 53 (2014) $14474-14484$.

[40] B. Feng, K. Xu, A. Huang, Synthesis of graphene oxide/polyimide mixed matrix membranes for desalination, RSC Adv. 7 (2017) 2211-2217.

[41] X. Zhao, O. Zhang, D. Chen, Enhanced Mechanical Properties of GrapheneBased Poly(vinyl alcohol) Composites, Macromolecules. 43 (2010) 2357-2363.

[42] S. Zereshki, A. Figoli, S.S. Madaeni, S. Simone, J.C. Jansen, M. Esmailinezhad, E. Drioli, Poly(lactic acid)/poly(vinyl pyrrolidone) blend membranes: Effect of membrane composition on pervaporation separation of ethanol/cyclohexane mixture, J. Memb. Sci. 362 (2010) 105-112.

[43] R. Castro-Muñoz, F. Galiano, V. Fíla, E. Drioli, A. Figoli, Matrimid®5218 dense membrane for the separation of azeotropic MeOH-MTBE mixtures by pervaporation, Sep. Purif. Technol. 199 (2018) 27-36.

[44] D.S.M. Constantino, R.P.V. Faria, A.M. Ribeiro, J.M. Loureiro, A.E. Rodrigues, Performance Evaluation of Pervaporation Technology for Process Intensification of Butyl Acrylate Synthesis, Ind. Eng. Chem. Res. 56 (2017) 13064-13074.

[45] R. Huang, C. Yeom, Pervaporation separation of aqueous mixtures using crosslinked poly(vinyl alcohol)(pva). II. Permeation of ethanol-water mixtures, J. Memb. Sci. 51 (1990) 273-292.

[46] T.F. Ceia, A.G. Silva, C.S. Ribeiro, J. V. Pinto, M.H. Casimiro, A.M. Ramos, J. Vital, PVA composite catalytic membranes for hyacinth flavour synthesis in a pervaporation membrane reactor, Catal. Today. 236 (2014) 98-107.

[47] C.H. Lee, W.H. Hong, Influence of different degrees of hydrolysis of poly ( vinyl 
alcohol ) membrane on transport properties in pervaporation of IPA / water mixture, J. Memb. Sci. 135 (1997) 187-193.

[48] S. Homaeigohar, M. Elbahri, Graphene membranes for water desalination, NPG Asia Mater. 9 (2017) e427.

[49] R.R. Nair, H.A. Wu, P.N. Jayaram, I.V. Grigorieva, A.K. Geim, Unimpeded Permeation of Water Through Helium-Leak-Tight Graphene-Based Membranes, Science (80-. ). 335 (2012) 442-445.

[50] K. Huang, G. Liu, W. Jin, Vapor transport in graphene oxide laminates and their application in pervaporation, Curr. Opin. Chem. Eng. 16 (2017) 56-64.

[51] S. Kumar Kannam, B.D. Todd, J.S. Hansen, P.J. Daivis, Slip length of water on graphene: Limitations of non-equilibrium molecular dynamics simulations, J. Chem. Phys. 136 (2012).

[52] K. Huang, G. Liu, Y. Lou, Z. Dong, J. Shen, W. Jin, A Graphene Oxide Membrane with Highly Selective Molecular Separation of Aqueous Organic Solution, Angew. Chemie - Int. Ed. 53 (2014) 6929-6932.

[53] W.S. Hung, Q.F. An, M. De Guzman, H.Y. Lin, S.H. Huang, W.R. Liu, C.C. Hu, K.R. Lee, J.Y. Lai, Pressure-assisted self-assembly technique for fabricating composite membranes consisting of highly ordered selective laminate layers of amphiphilic graphene oxide, Carbon N. Y. 68 (2014) 670-677.

[54] F. Galiano, F. Falbo, A. Figoli, Polymeric Pervaporation Membranes : OrganicOrganic Separation, in: O. Visakh, P. Nazarenko (Eds.), Nanostructured Polym. Membr., Scrivener Publishing LLC, Massachusetts, United States, 2016: pp. 281304. 
870

871

872

873

874

875

876

877

878

879

880

881

882

883

884

885

886

887

888

[55] R.W. Baker, J.G. Wijmans, Y. Huang, Permeability, permeance and selectivity: A preferred way of reporting pervaporation performance data, J. Memb. Sci. 348 (2010) 346-352.

[56] D. Yang, J. Li, Z. Jiang, L. Lu, X. Chen, Chitosan/TiO2 nanocomposite pervaporation membranes for ethanol dehydration, Chem. Eng. Sci. 64 (2009) 3130-3137.

[57] S.D. Bhat, T.M. Aminabhavi, Pervaporation-Aided Dehydration and Esterification of Acetic Acid with Ethanol Using 4A Zeolite-Filled Cross-linked Sodium AlginateMixed Matrix Membranes, J. Appl. Polym. Sci. 113 (2009) 157-168.

[58] Y.L. Liu, C.Y. Hsu, Y.H. Su, J.Y. Lai, Chitosan-silica complex membranes from sulfonic acid functionalized silica nanoparticles for pervaporation dehydration of ethanol-water solutions, Biomacromolecules. 6 (2005) 368-373.

[59] M.S. Schehlmann, E. Wiedemann, R.N. Lichtenthaler, Pervaporation and vapor permeation at the azeotropic point or in the vicinity of the LLE boundary phases of organic / aqueous mixtures, J. Memb. Sci. 107 (1995) 277-282.

[60] D. Van Baelen, B. Van Der Bruggen, K. Van Den Dungen, J. Degreve, C. Vandecasteele, Pervaporation of water - alcohol mixtures and acetic acid - water mixtures, Chem. Eng. Sci. 60 (2005) 1583-1590. 
Figure 1. Pure cross-linked PVA membrane and its MMMs-GO with 1 wt. \% of filler.

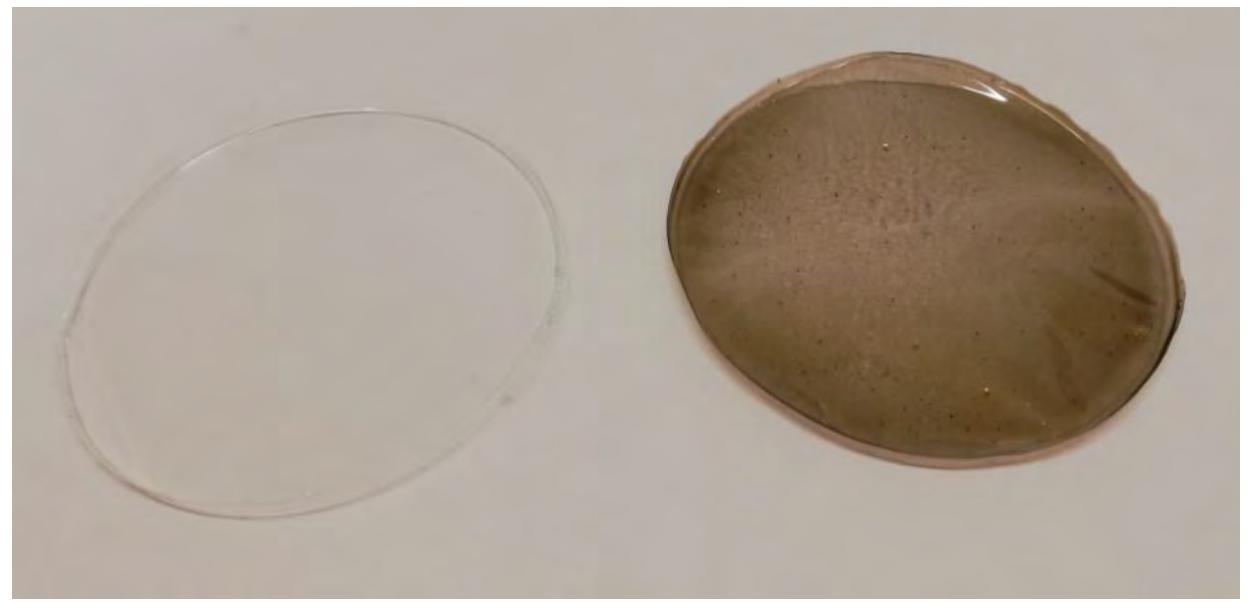


Table 1. $T_{g}$ and contact angle (CA) values of the pure cross-linked PVA membranes and its MMMs-GO.

\begin{tabular}{lll}
\hline Membrane & $T_{g}\left({ }^{\circ} \mathrm{C}\right)$ & $\mathrm{CA}\left({ }^{\circ}\right)$ \\
Pure cross-linked PVA & $95.6 \pm 2.8$ & $69.6 \pm 0.5$ \\
Cross-linked PVA + 1 wt.\% GO & $104.3 \pm 0.9$ & $59.9 \pm 1.2$ \\
Cross-linked PVA + 2 wt. \% GO & $109.6 \pm 1.4$ & $58.4 \pm 0.5$ \\
\hline
\end{tabular}


Figure 2. Surface and cross-section FESEM images of pure cross-linked PVA $(a, b)$ and MMMs at 1 wt.\% (c, d) and 2 wt.\% (e, f) GO content, respectively.
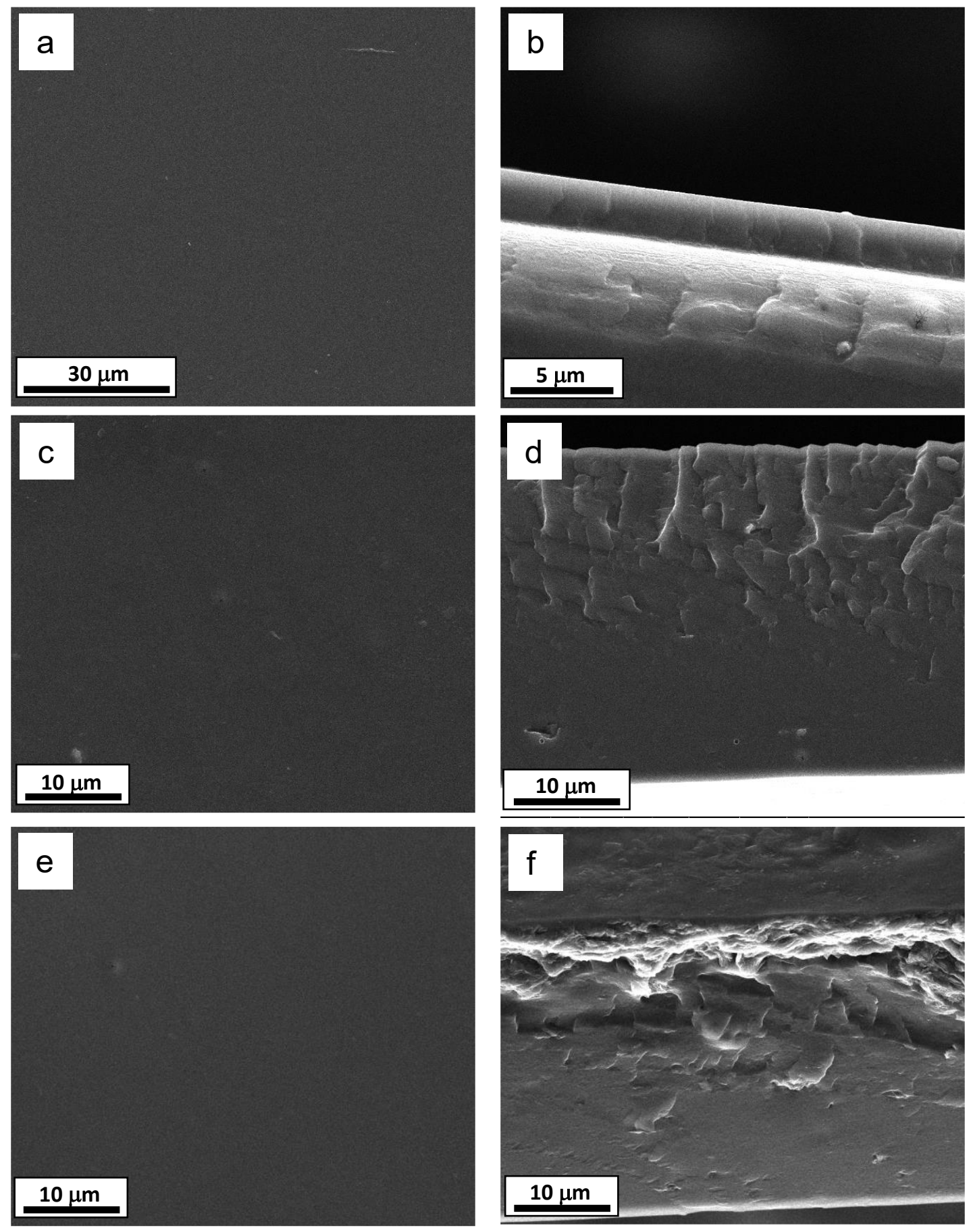
Figure 3. TEM images of GO flakes (a), distribution of GO flakes in MMM (b), GO flake in MMM observed at different angles $-26^{\circ}, 0^{\circ}$ and $27^{\circ}$ (c), GO flakes in MMM and Fourier transform of the selected zone.

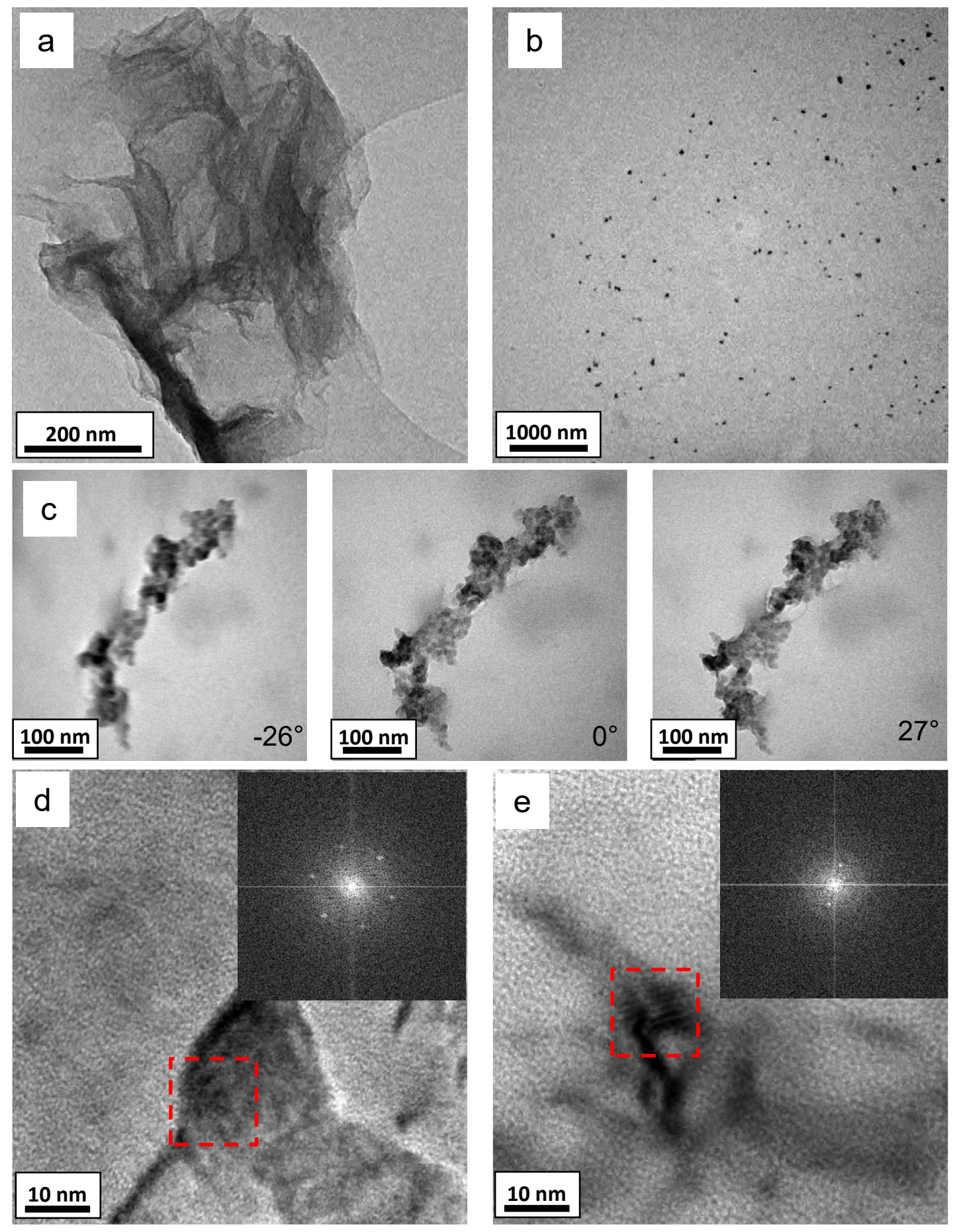


Figure 4. XRD patterns of the pure PVA, pure GO, cross-linked PVA and its MMMs-GO.

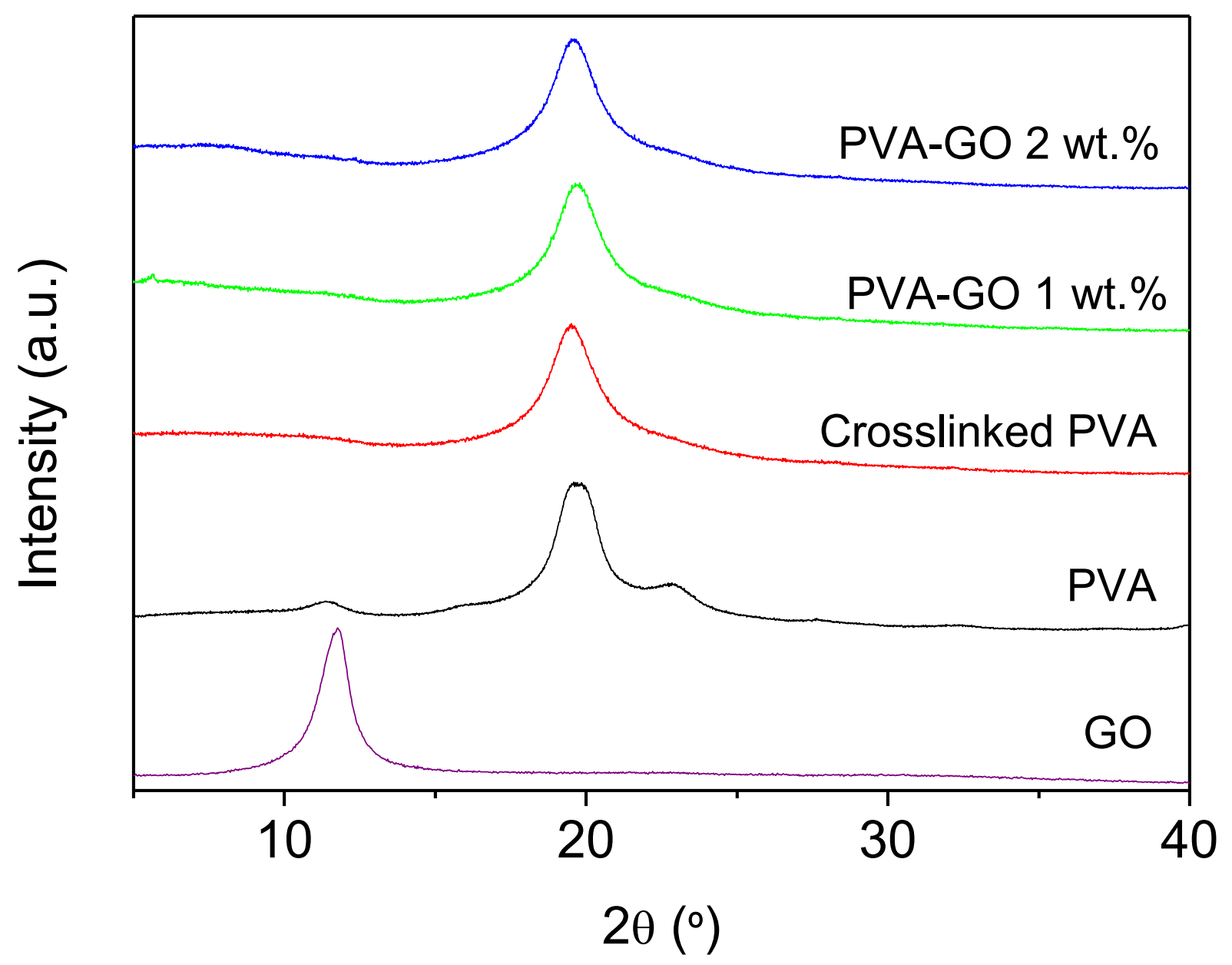


Figure 5. FTIR spectroscopy of the GO, glutaraldehyde, pristine PVA, cross-linked PVA and the PVA-GO 1 wt.\% samples.

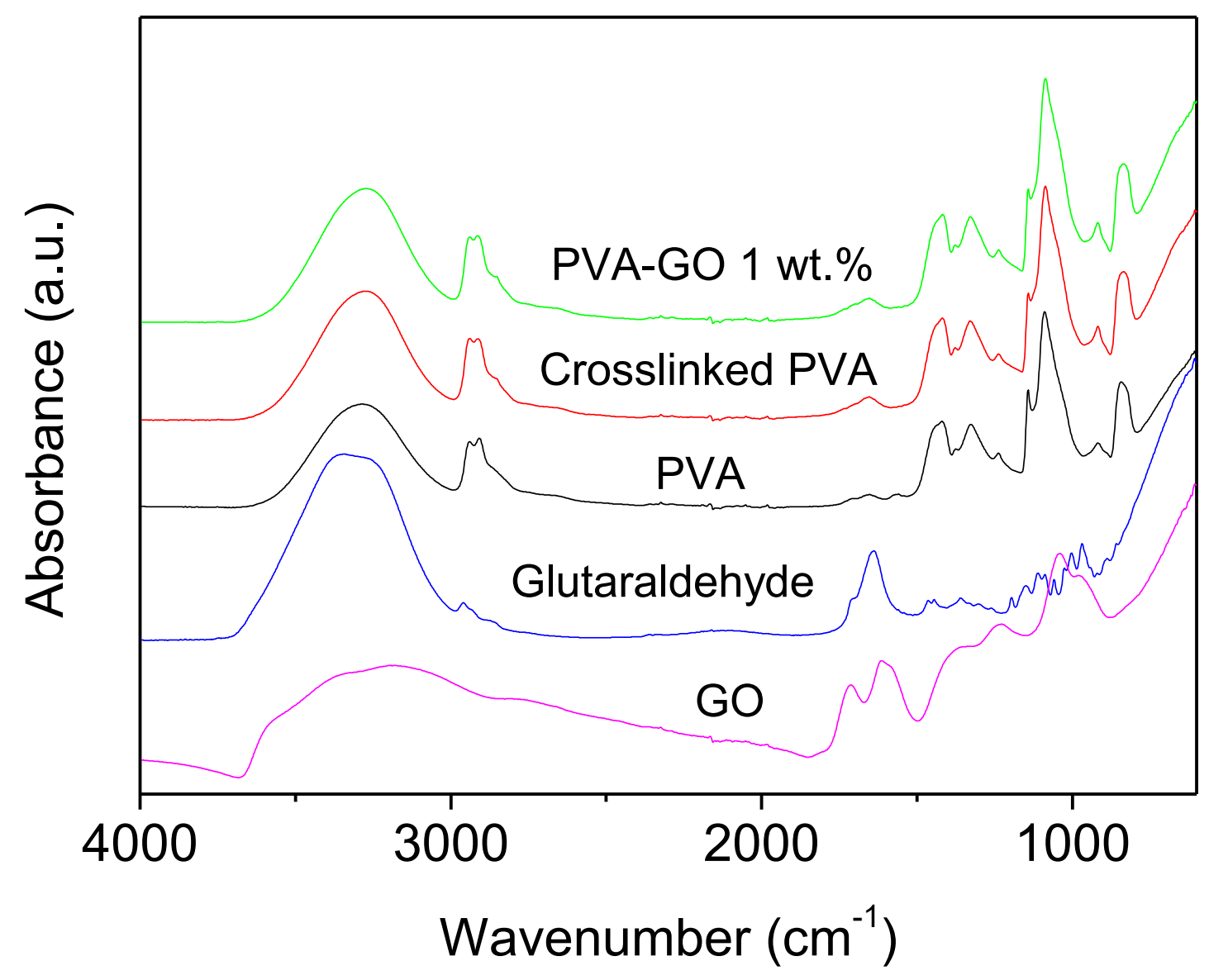


Figure 6. Uptake of the cross-linked PVA membrane and MMMs-GO at 10:90 wt. $\%$ water-ethanol (at $\left.40^{\circ} \mathrm{C}\right)$.

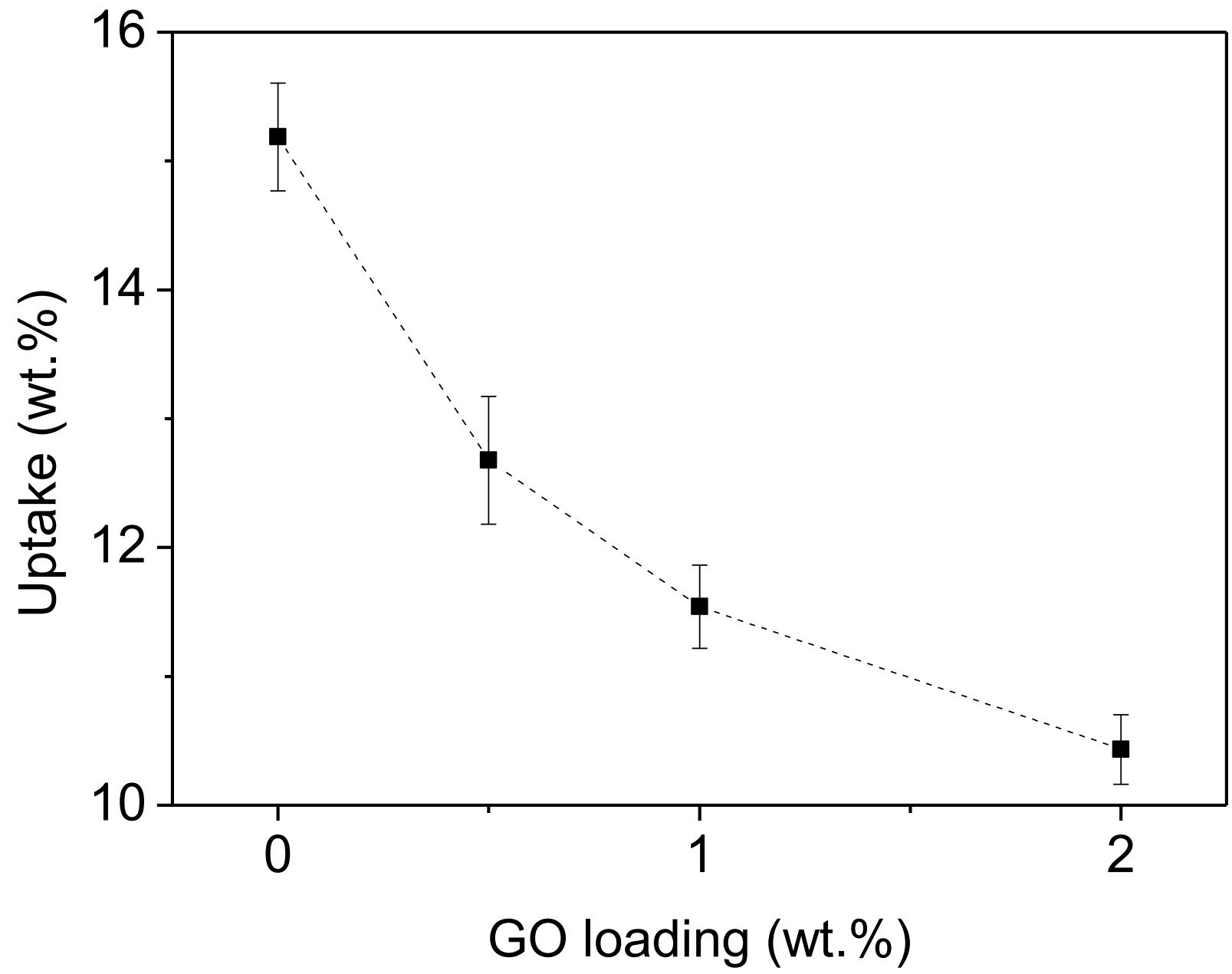


Figure 7. Mechanical properties of cross-linked PVA membrane and MMMs-GO before and after exposure to water-ethanol (10:90 wt.\%) mixture.
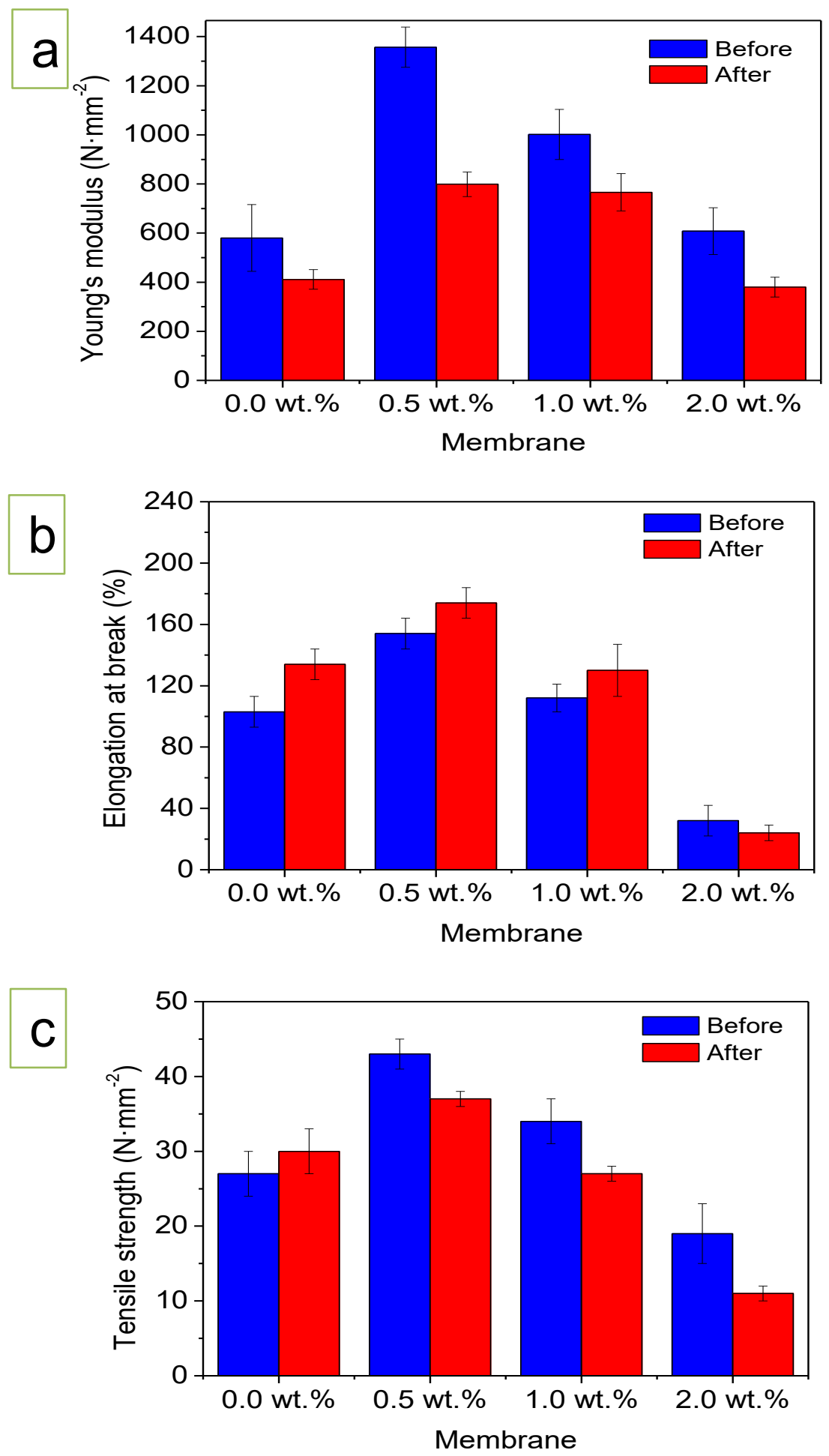
Figure 8. Total permeate flux as a function of the GO loading at different operating temperatures (10: 90 wt.\% water-ethanol). The curves are only guides to the eye.

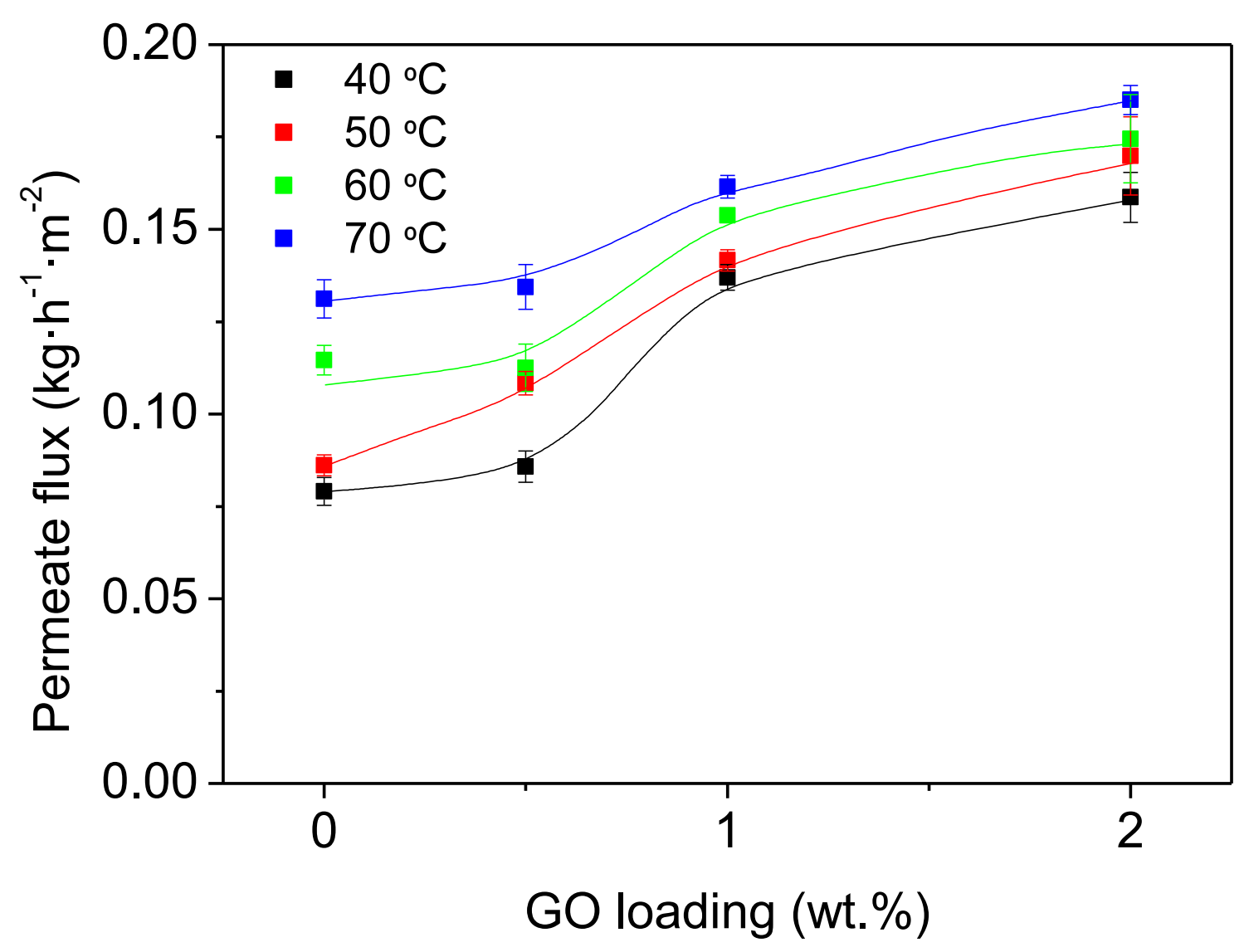


Table 2. Apparent activation energies for total permeate, water and ethanol partial fluxes of the PVA membrane and its MMMs at different GO loadings (Data obtained from Figures S3-S5).

\begin{tabular}{llll}
\hline & \multicolumn{2}{l}{$\begin{array}{l}\text { Activation energy values } \\
(\mathbf{k J} / \mathbf{m o l})\end{array}$} \\
\cline { 2 - 4 } Go loading (wt.\%) & Total & Water & \\
\hline $\mathbf{0}$ & & & \\
$\mathbf{0 . 5}$ & 7.0 & 6.5 & 22.0 \\
$\mathbf{1}$ & 5.3 & 5.3 & 17.3 \\
$\mathbf{2}$ & 2.2 & 1.6 & 15.2 \\
\hline
\end{tabular}


Figure 9. Separation factor as a function of the GO loading at different operating temperatures (10:90 wt.\% water-ethanol). The lines are only guides to the eye.

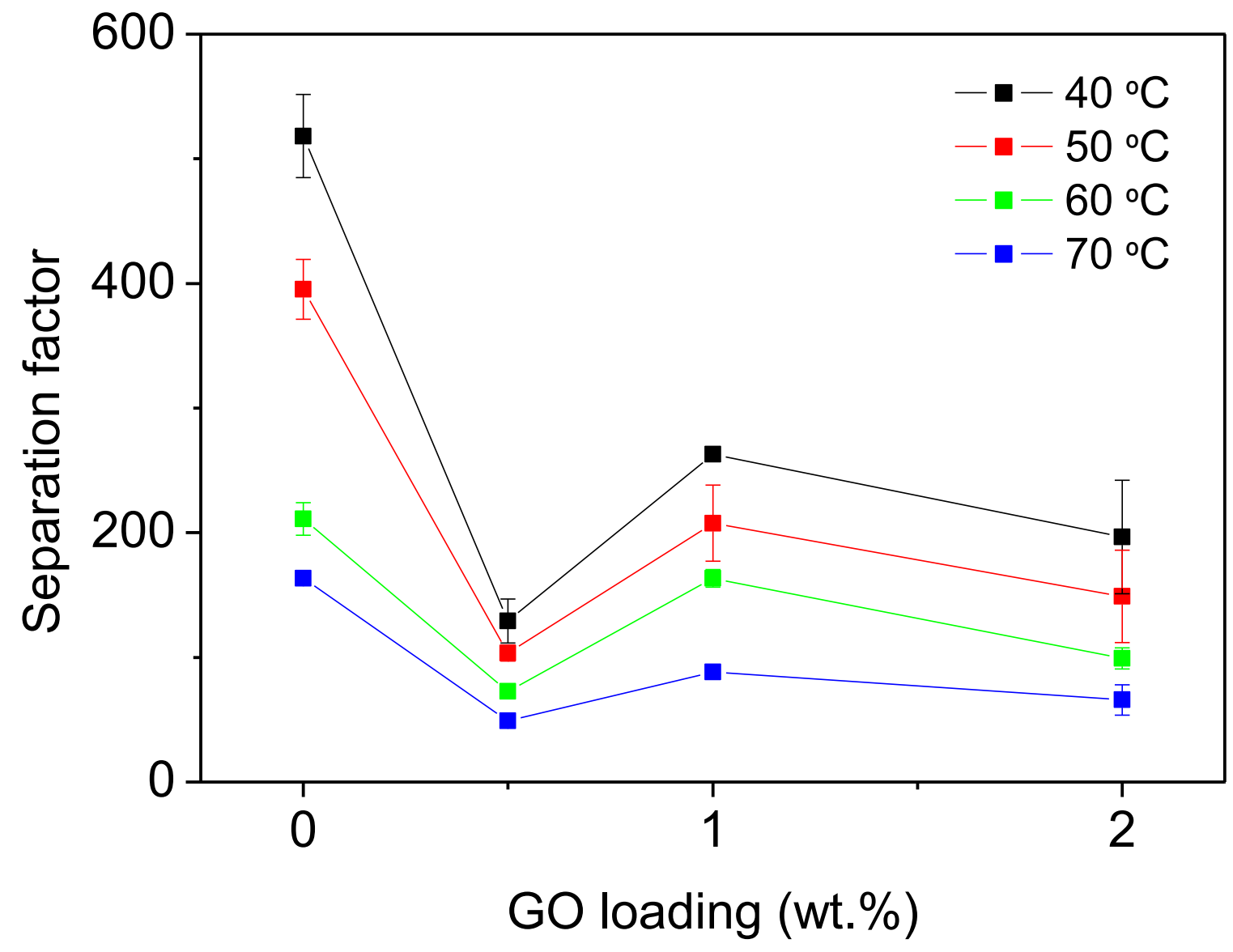


Figure 10. Water and ethanol partial fluxes as a function of the GO loading at different operating temperatures (10:90 wt.\% water-ethanol). The curves are only guides to the eye.

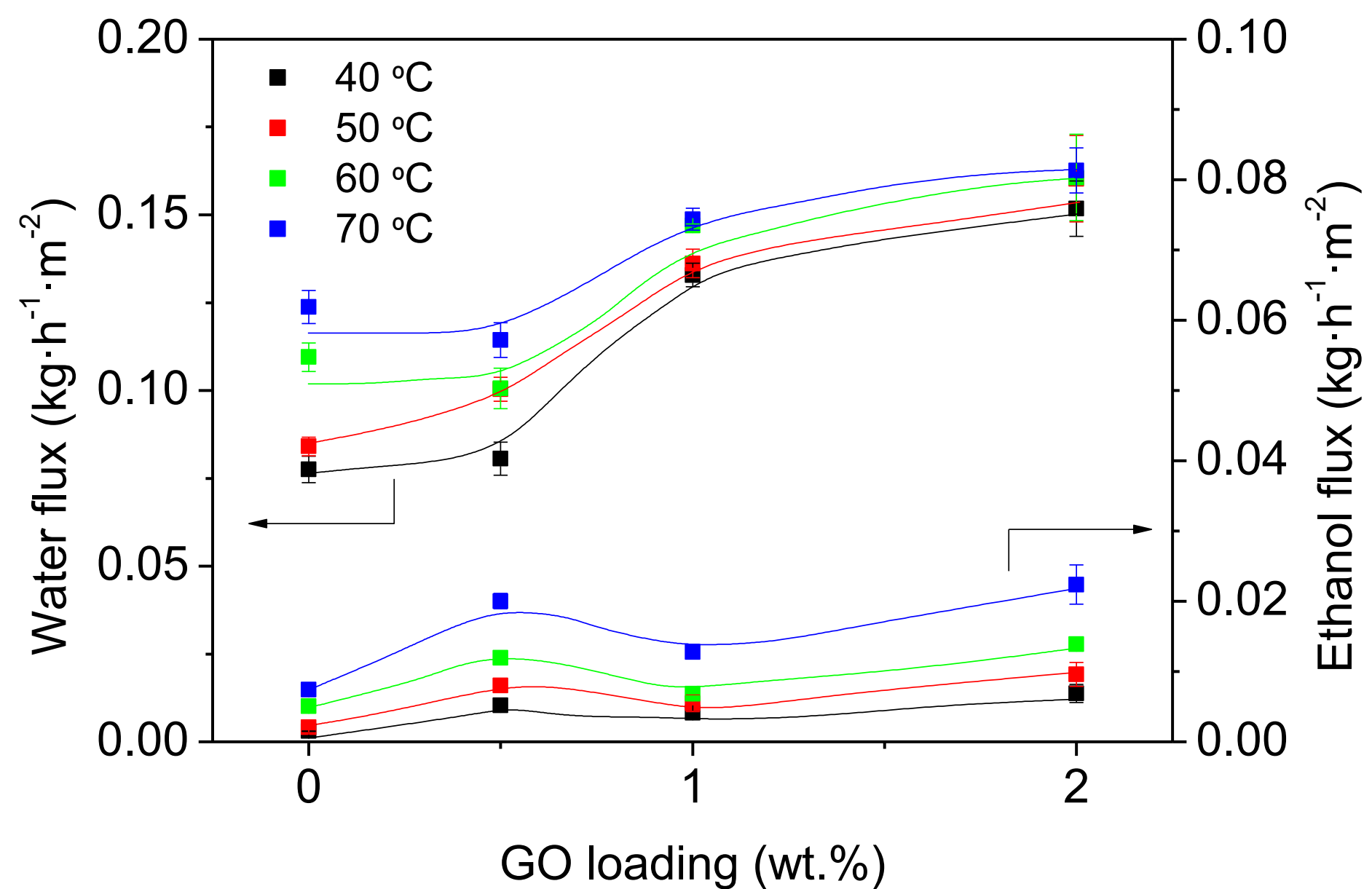


Figure11. Schematic drawing of the hypothetic water permeation mechanism through GO laminates.Inspired by Nair et al. [49]

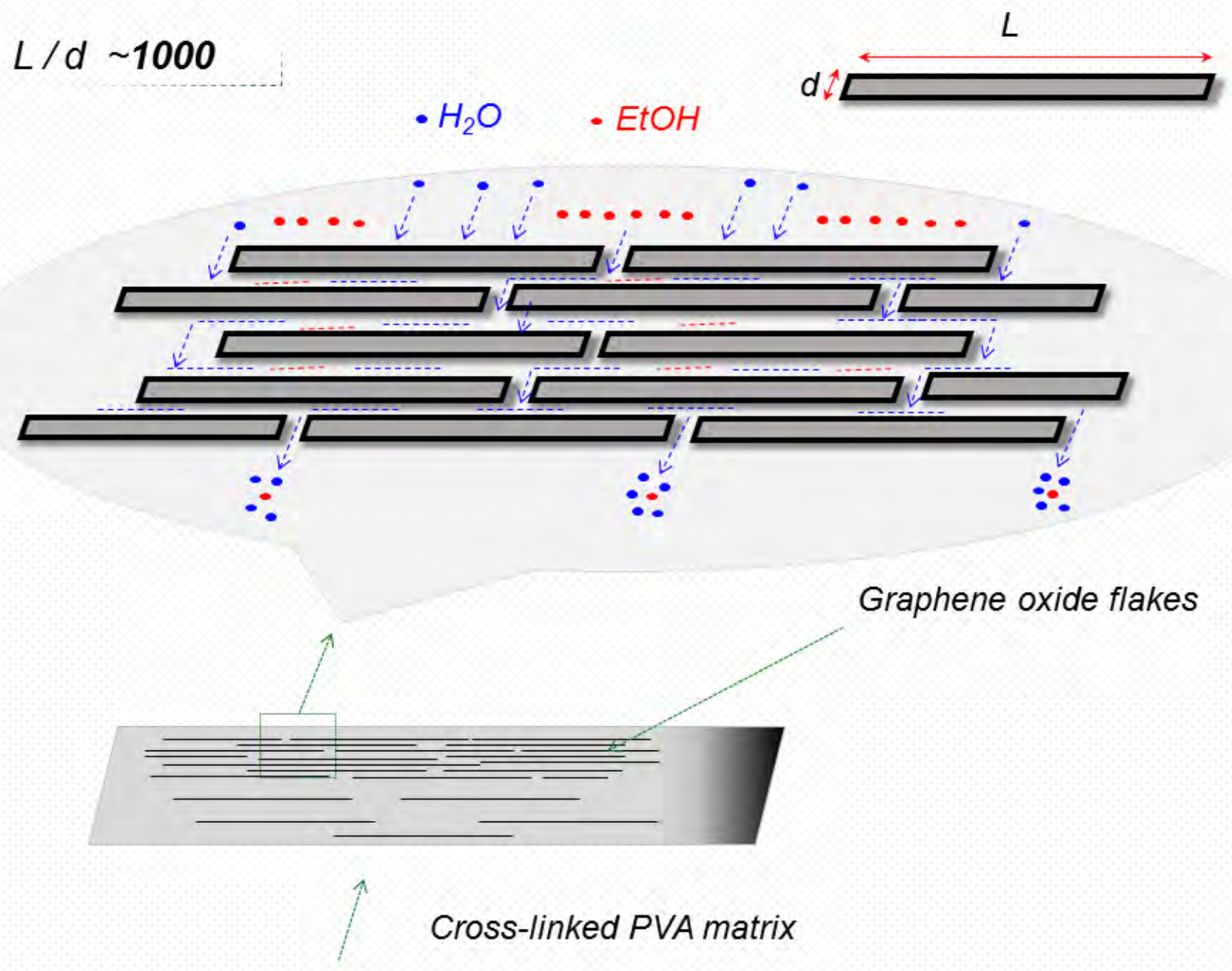


Table 3. Comparison of the cross-linked PVA-GO MMMs performance with other studies for the dehydration of ethanol.

\begin{tabular}{|c|c|c|c|c|c|c|c|}
\hline Mixed matrix membrane & Filler loading: & Mixture concentration: & Operating conditions: & $\begin{array}{l}\mathrm{J} \\
\left(\mathrm{kg} \mathrm{m}^{-2} \mathrm{~h}^{-1}\right)\end{array}$ & $\begin{array}{l}\text { Separation } \\
\text { factor } \\
(\alpha)\end{array}$ & PSI & Reference: \\
\hline $\begin{array}{ll}\text { Cross-linked } & \text { PVA-filled } \\
\text { GO } & \end{array}$ & 1 wt. $\%$ & $\begin{array}{l}10 \text { wt. } \% \mathrm{H}_{2} \mathrm{O} \\
90 \text { wt. } \% \mathrm{EtOH}\end{array}$ & $40^{\circ} \mathrm{C}, 3 \mathrm{mbar}$ & 0.137 & 263 & 36.0 & This work \\
\hline $\begin{array}{l}\text { Cross-linked PVA-filled } \\
\text { GO }\end{array}$ & 2 wt. $\%$ & $\begin{array}{l}10 \text { wt. } \% \mathrm{H}_{2} \mathrm{O} \\
90 \text { wt. \% EtOH }\end{array}$ & $70^{\circ} \mathrm{C}, 3$ mbar & 0.185 & 65.9 & 12.2 & This work \\
\hline Chitosan-filled H-ZSM-5 & 8 wt. $\%$ & $\begin{array}{l}10 \text { wt. } \% \mathrm{H}_{2} \mathrm{O} \\
90 \text { wt. } \% \text { EtOH }\end{array}$ & $80^{\circ} \mathrm{C}, 10 \mathrm{mbar}$ & 0.230 & 152 & 35.0 & [13] \\
\hline $\begin{array}{l}\text { Cross-linked sodium } \\
\text { alginate-filled beta zeolite }\end{array}$ & 10 wt. $\%$ & $\begin{array}{l}10 \text { wt. } \% \mathrm{H}_{2} \mathrm{O} \\
90 \text { wt. } \% \text { EtOH }\end{array}$ & $30^{\circ} \mathrm{C}, 0.6 \mathrm{mbar}$ & 0.130 & 1600 & 208.0 & {$[11]$} \\
\hline Polyimide-filled ZIF-8 & 12 wt. $\%$ & $\begin{array}{l}10 \text { wt. } \% \mathrm{H}_{2} \mathrm{O} \\
90 \text { wt. } \% \text { EtOH }\end{array}$ & $42^{\circ} \mathrm{C}, 44$ mbar & 0.260 & 300 & 78.0 & {$[6]$} \\
\hline $\begin{array}{l}\text { Cross-linked sodium } \\
\text { alginate-filled beta zeolite }\end{array}$ & 10 wt. $\%$ & $\begin{array}{l}10 \text { wt. } \% \mathrm{H}_{2} \mathrm{O} \\
90 \text { wt. } \% \mathrm{EtOH}\end{array}$ & $30^{\circ} \mathrm{C}, 0.6 \mathrm{mbar}$ & 0.138 & 1334 & 184.1 & {$[57]$} \\
\hline PVA-filled MWCNT & 5 wt. $\%$ & $\begin{array}{l}10 \text { wt. } \% \mathrm{H}_{2} \mathrm{O} \\
90 \text { wt. } \% \text { EtOH }\end{array}$ & $40^{\circ} \mathrm{C}, 1.3$ mbar & 0.080 & 500 & 40.0 & [15] \\
\hline
\end{tabular}




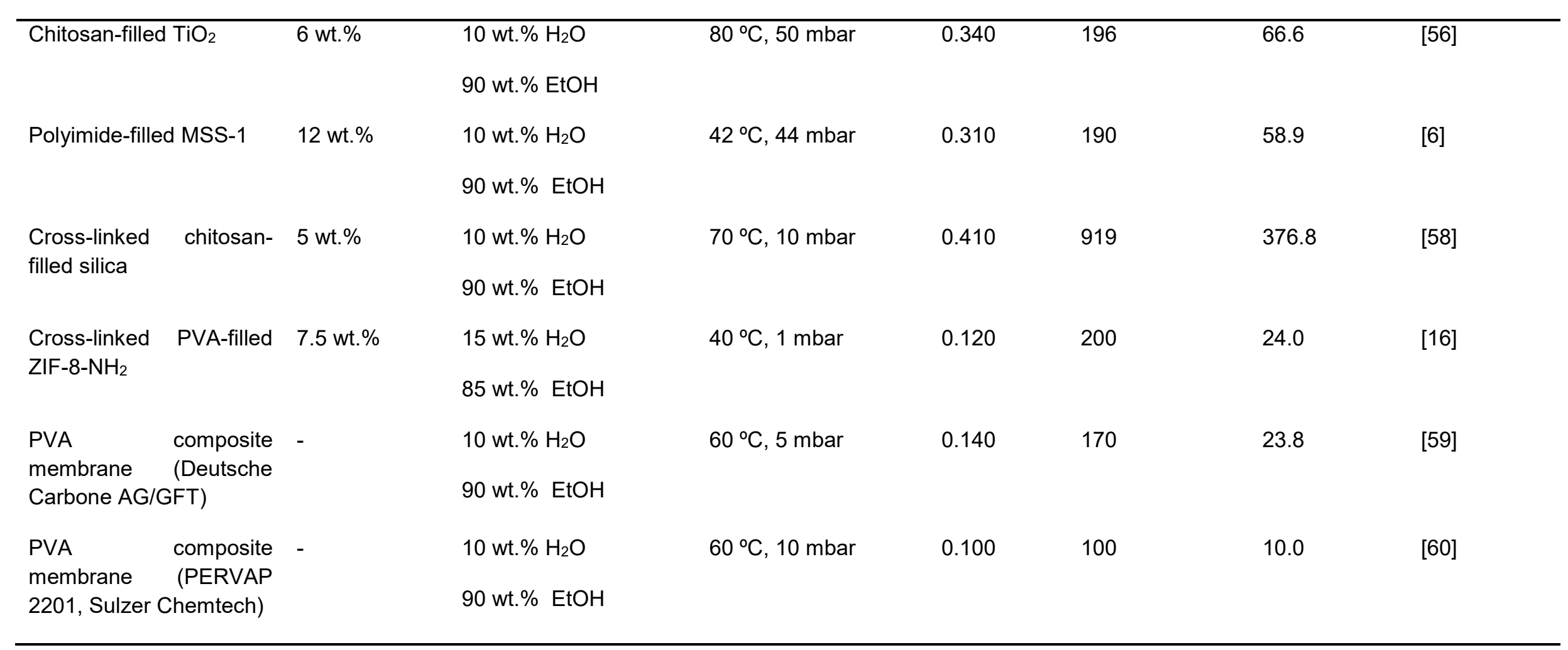

